\title{
TWR Bench-Scale Steam Reforming Demonstration
}

D. W. Marshall

N. R. Soelberg

May 2003

Idaho National Engineering and Environmental Laboratory Bechtel BWXT Idaho, LLC 


\section{TWR Bench-Scale Steam Reforming Demonstration}

D. W. Marshall

N. R. Soelberg

May 2003

Idaho National Engineering and Environmental Laboratory Idaho Falls, Idaho 83415

Prepared for the

U.S. Department of Energy

Assistant Secretary for Environment Management

Under DOE Idaho Operations Office

Contract DE-AC07-99ID13727 


\begin{abstract}
The Idaho Nuclear Technology and Engineering Center (INTEC) was home to nuclear fuel reprocessing activities for decades at the Idaho National Engineering and Environmental Laboratory. As a result of the reprocessing activities, INTEC has accumulated approximately one million gallons of acidic, radioactive, sodium-bearing waste (SBW). The purpose of this demonstration was to investigate a reforming technology, offered by ThermoChem Waste Remediation, LLC, (TWR) for treatment of SBW into a "road ready" waste form that would meet the waste acceptance criteria for the Waste Isolation Pilot Plant (WIPP). TWR is the licensee of Manufacturing Technology Conversion International (MTCI) steam-reforming technology in the field of radioactive waste treatment. A non-radioactive simulated SBW was used based on the known composition of waste tank WM-180 at INTEC. Rhenium was included as a non-radioactive surrogate for technetium.

Data were collected to determine the nature and characteristics of the product, the operability of the technology, the composition of the off-gases, and the fate of key radionuclides (cesium and technetium) and volatile mercury compounds. The product contained a low fraction of elemental carbon residues in the cyclone and filter vessel catches. Mercury was quantitatively stripped from the product but cesium, rhenium (Tc surrogate), and the heavy metals were retained. Nitrate residues were about $400 \mathrm{ppm}$ in the product and $\mathrm{NO}_{\mathrm{x}}$ destruction exceeded $86 \%$. The demonstration was successful.
\end{abstract}




\section{SUMMARY}

ThermoChem Waste Remediation, LLC (TWR) was awarded a contract to demonstrate its reforming technology on non-radioactive, simulated tank WM-180 sodium-bearing waste using government furnished equipment, built and operated by Science Applications International Corporation (SAIC) in Idaho Falls, Idaho. TWR specified the flowsheet conditions and provided proprietary additives for the demonstration. Performance dates were December 2 through December 22, 2002, to conduct preliminary optimization tests and execute a successful 100-hour demonstration run.

After a few days of proving and optimizing the flowsheet conditions, the demonstration run was started December 9 and completed December 14, 2002. Processing was interrupted for brief periods due to equipment and software malfunctions unrelated to the TWR reforming technology. The 100-hr demonstration run was successfully completed. The sodium-bearing waste simulant was converted into a freely-flowing powder and $\mathrm{NO}_{\mathrm{x}}$ destruction was very good. Details of the process flowsheet and data collected on product and off-gas characteristics are contained within the report. 


\section{ACKNOWLEDGMENTS}

The demonstration test is a product of diligent efforts from many persons in several different organizations. Test system design and construction, and test operation, was funded by the U.S. Department of Energy through the Idaho National Engineering and Environmental Laboratory (INEEL) High Level Waste Program Idaho Tank Farm Project. The INEEL designed and fabricated the reformer vessel, provided a high-level design for the complete process, and directed the test system installation at the SAIC Science and Technology Application Research (STAR) Center in Idaho Falls, Idaho. SAIC completed the design of the process, coordinated the procurement and receipt of equipment and materials, fabricated and assembled the components, wrote the operating procedures, provided the facility to house the test unit, and operated the unit. Eldredge Engineering provided significant consultation on the fluidized bed design, operation, and calculated the mass balance. Last but not least, the authors thank the contributions of TWR and Manufacturing Technology Conversion International (MTCI) for their technological innovations that were the basis of the demonstration test and their oversight during the performance of the tests.

The coauthors would also like to thank the following persons from the INEEL for their direct contributions to the success of this project:

- $\quad$ Arlin Olson who represented the interests of the Idaho Tank Farm Project and directed the overall technology development effort.

- Wayne Ridgeway who, as the project engineer, managed fiscal and human resources and directed the test facility design and construction.

- Bob Crowton who provided procurement services.

- $\quad$ Curtis St. Michel, Ervin Brubaker, and Paul Petersen who provided the process monitoring, control, and data logging systems.

- $\quad$ Sylvester Losinski who assisted test planning and oversight during operation.

- $\quad$ Kevin Shaber who provided material specifications, and assisted in the procurement, design, and assembly of the reformer vessel.

- $\quad$ Michael Phippen and Wade Waddoups who fabricated the reformer and obtained off-site machining services. 


\section{CONTENTS}

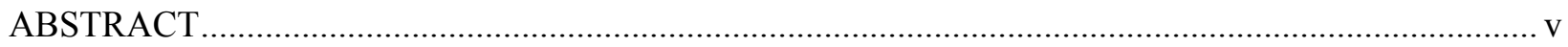

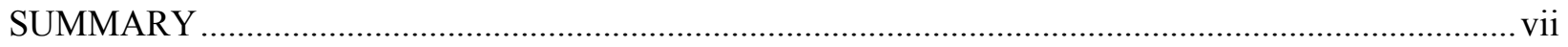

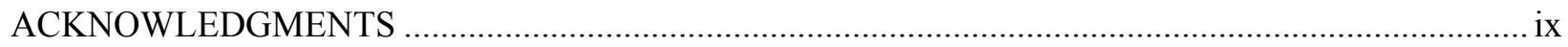

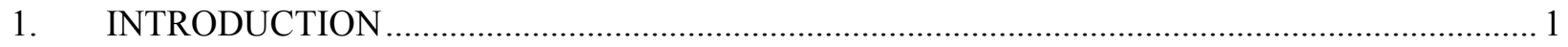

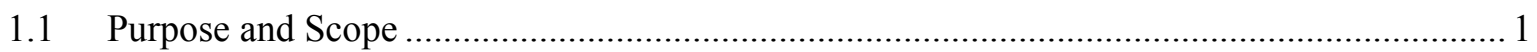

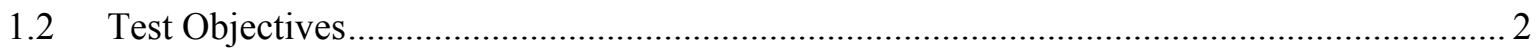

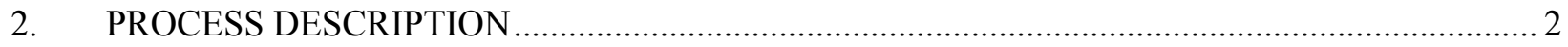

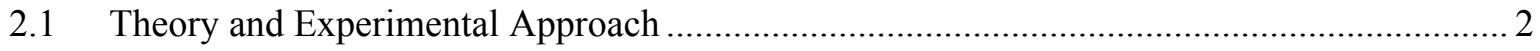

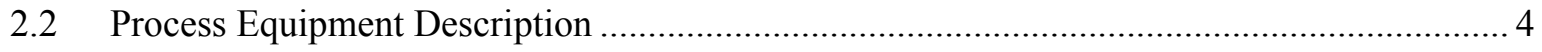

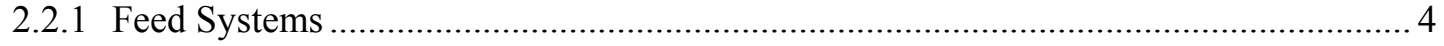

2.2.2 Bench-Scale Reformer Description ...................................................................... 4

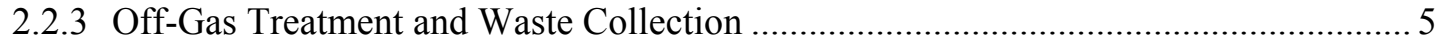

2.2.4 Data Acquisition and Control System ……...........................................................

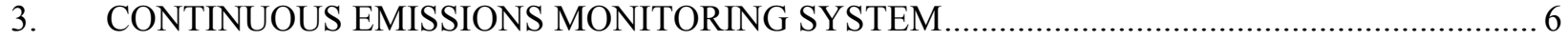

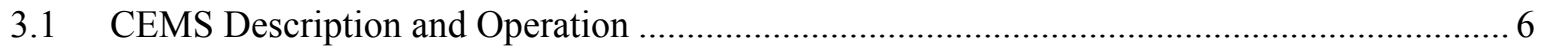

3.2 Off-gas Measurement Accuracy, Calibrations, and Quality Assurance Checks .................... 6

3.3 $\quad \mathrm{NO}_{\mathrm{x}}$ Analyzer Performance, Calibrations, and Quality Control ........................................ 9

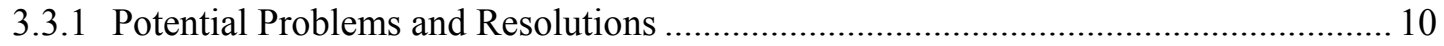

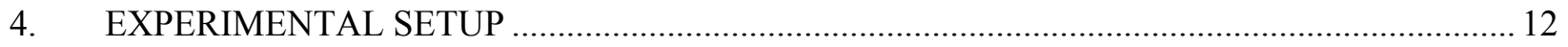

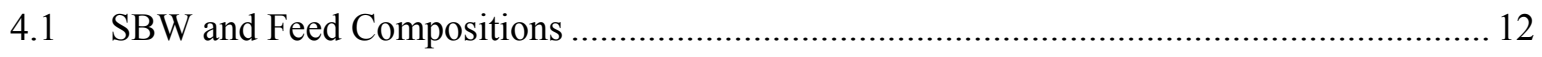

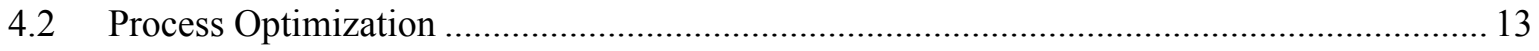

4.3 Technology Demonstration Test Parameters …........................................................... 13

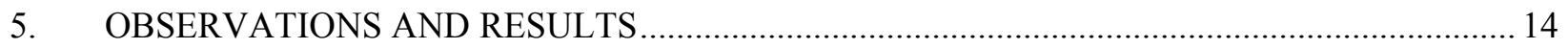

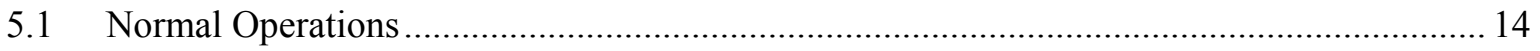

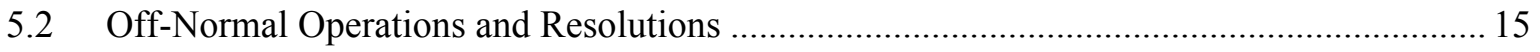

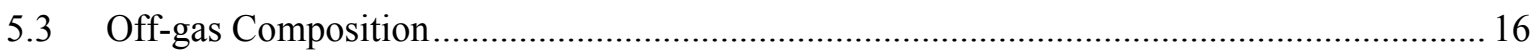

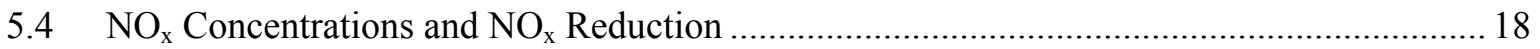

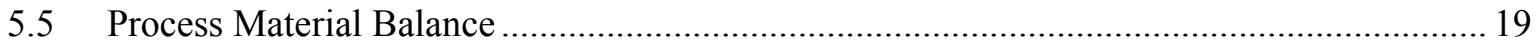




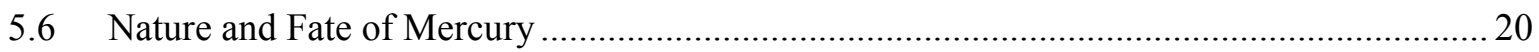

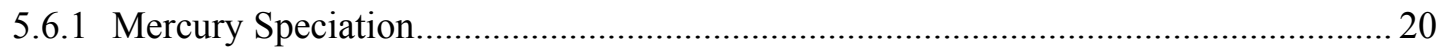

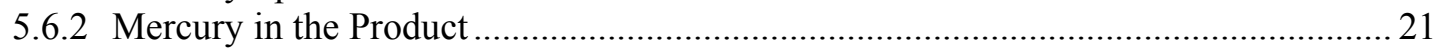

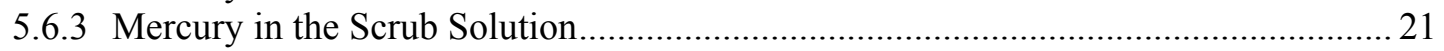

5.6.4 Mercury Captured on the Granular Activated Carbon............................................. 21

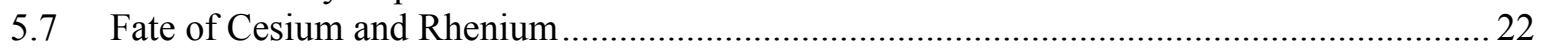

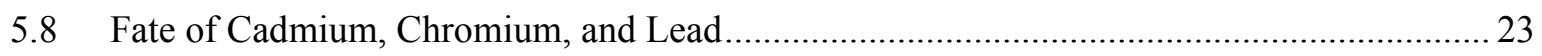

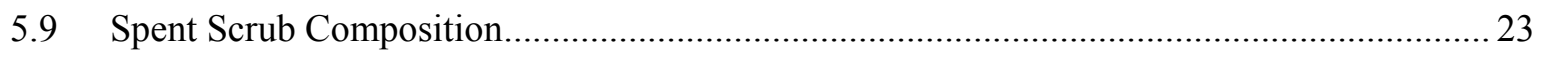

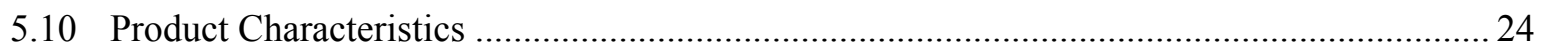

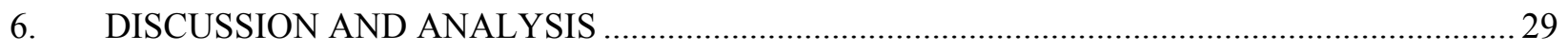

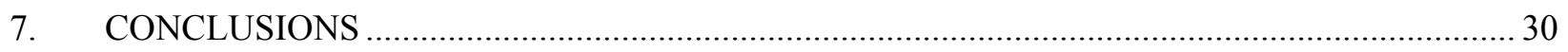

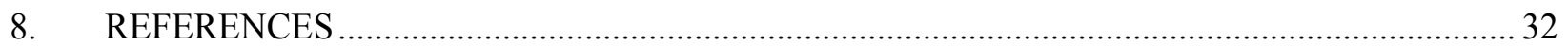

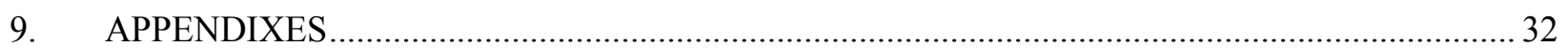

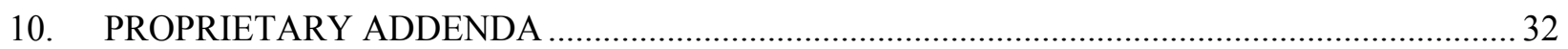

\section{FIGURES}

Figure 1. Steam reforming process flow diagram........................................................................ 3

Figure 2. Continuous emissions monitoring system used during the TWR steam reformer 100 -hr test. ..... 7

Figure 3. $\mathrm{O}_{2}, \mathrm{CO}, \mathrm{H}_{2}$, and $\mathrm{CH}_{4}$ composition measurements for the TWR steam reformer 100-hr test. ..... 17

Figure 4. Corrected $\mathrm{NO}_{\mathrm{x}}$ composition measurements for the TWR steam reformer 100-hr test. .............. 17

Figure 5. $\mathrm{NO}_{\mathrm{x}}$ reduction for the TWR steam reformer 100-hr test.................................................... 19

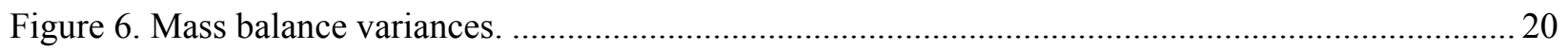

Figure 7. Cesium to rhenium mass ratio in the scrub solution.............................................................. 23

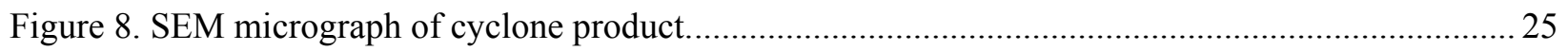

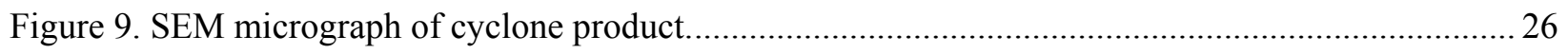

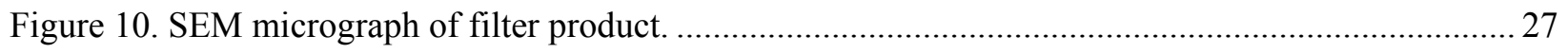

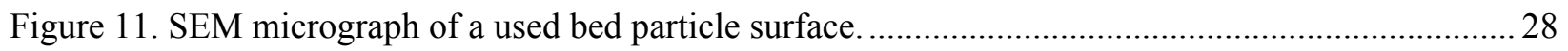




\section{TABLES}

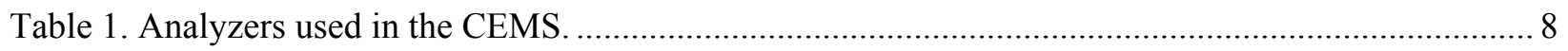

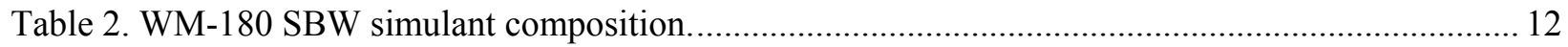

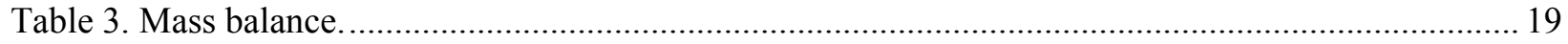

Table 4. Organic compounds identified in the scrubber emulsion....................................................... 24

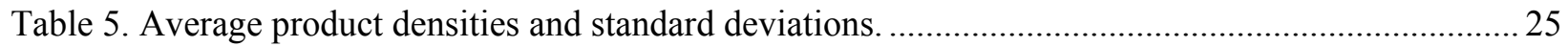

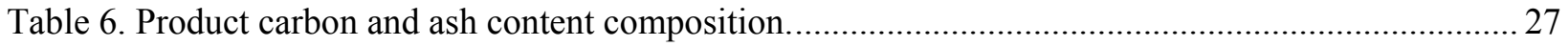

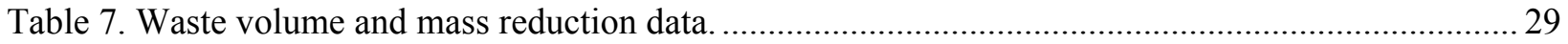




\section{ACRONYMS}

BMC Bed Medium Constituent

CAI California Analytical Instruments

CEM continuous emissions monitor(ing)

CEMS continuous emissions monitoring system

COT Cumulative operating time

DAS data acquisition system

EPA Environmental Protection Agency

GAC granular activated carbon

GUI graphical user interface

INEEL Idaho National Engineering and Environmental Laboratory

INTEC Idaho Nuclear Technology and Engineering Center

LFL lower flammability limit

MACT Maximum Achievable Control Technology

MTCI Manufacturing Technology Conversion International

MTEC Maximum Theoretical Emission Concentration

NAR nozzle atomizing ratio

PLC programmable logic controller

RCRA Resource Conservation and Recovery Act

SAIC Science Applications International Corporation

SBW sodium-bearing waste

SCR selective catalytic reduction

SEM scanning electron microscope

STAR Science and Technology Applications Research

SVOC semi-volatile organic compound

TECO Thermo Environmental Instruments, Inc.

THC total hydrocarbons

TWR ThermoChem Waste Remediation

UDS undissolved solids

VOC volatile organic compound

WIPP Waste Isolation Pilot Plant 


\section{TWR Bench-Scale Steam Reforming Demonstration}

\section{INTRODUCTION}

The Idaho Nuclear Technology and Engineering Center (INTEC) was home to nuclear fuel reprocessing activities for decades until recovery of unspent uranium was halted in the 1990s. As a result of the reprocessing activities, INTEC has accumulated approximately one million gallons of acidic, radioactive, sodium-bearing waste (SBW). To date, the raffinates from reprocessing activities and much of the SBW have been calcined into a powder for storage pending final treatment. Further treatment of the SBW inventory is on hold pending a review and determination of the most appropriate treatment method. Steam reforming is a candidate technology that is being investigated for treatment of the SBW into a "road ready" waste form that can be shipped to the Waste Isolation Pilot Plant (WIPP) in New Mexico for internment.

Calcination of the SBW resulted in visibly brown emissions of nitrogen oxides $\left(\mathrm{NO}_{\mathrm{x}}\right)$, required the recycle of high-mercury scrub solutions to the waste tanks and did not employ Maximum Achievable Control Technology (MACT) to control gaseous emissions. Any alternative technologies that may be deployed for the treatment of SBW must be capable of meeting air quality standards and emission limits, and avoid the generation of secondary wastes that cannot be readily treated and dispositioned with the treated SBW.

\subsection{Purpose and Scope}

The purpose of this demonstration was to investigate the proprietary ThermoChem Waste Remediation (TWR) reforming technology (patented by Manufacturing Technology Conversion International [MTCI]) as applied to the treatment of a simulated SBW. Data were collected to determine the nature and characteristics of the product, the operability of the technology, the composition of the off-gases, and the fates of key radionuclides (cesium and technetium) and Resource Conservation and Recovery Act (RCRA) metals such as mercury.

For the purpose of this demonstration, a simulant was formulated to represent the SBW contained in waste tank WM-180 at INTEC. All components of the simulated SBW were non-radioactive or naturally occurring isotopes in their natural isotopic distributions. Rhenium was included as a non-radioactive surrogate for technetium. Concentrations of non-radioactive cesium and rhenium were inflated to facilitate detection in the product and off-gas scrub solution.

The scope of this demonstration was to configure and operate a government-furnished test platform in accordance with process conditions/parameters and using the process additives specified/provided by TWR. TWR was granted one week to ensure equipment, procedures, and materials were staged and ready for the demonstration, followed by a two-week period to execute a successful 100-hr demonstration on the equipment at nominally steady-state conditions.

During the later part of the first week, TWR observed the operation of the process and requested adjustments to the operating parameters, based on the response of the equipment, to establish desired operating conditions and parameters for the demonstration test. The demonstration test was conducted the second week and consisted of 100 cumulative hours of feeding the blended simulated WM-180 solution to the reformer. Although the feed was shut off a few times for brief periods because of software and hardware failures, the 100-hr demonstration run was successfully completed. None of the temporary shutdowns were a result of the TWR flowsheet. 


\subsection{Test Objectives}

The primary and overriding objective of the demonstration test was to demonstrate (not develop) the TWR's reforming technology for the treatment of simulated SBW.

Other primary objectives of the demonstration test were to:

- $\quad$ Show the fluidized-bed steam reformer can be operated to treat simulated SBW without serious agglomeration of bed particles or de-fluidization

- Characterize the composition, sizes, and behavior of the solid product(s). This will include the absence of free liquids in the product, waste loading, process throughput, and process operability

- Characterize the composition of the off-gas after filtration

- $\quad$ Determine the fate of cesium, rhenium (Tc surrogate), and mercury speciation

- Quantify nitrate destruction and $\mathrm{NO}_{\mathrm{x}}$ emissions.

Secondary objectives included determining the effectiveness of granular activated carbon (GAC) for the capture of mercury volatiles from the off-gas and quantifying accumulation of organic carbon in the scrub. The off-gas treatment system was not intended to be fully representative of a treatment system that would be employed on a full-scale steam reforming system. As such, the efficiency of the GAC and scrubber may not be good indicators of the performance expected from a full-scale system.

\section{PROCESS DESCRIPTION}

\subsection{Theory and Experimental Approach}

The TWR/MTCI process consists of a fluidized bed reactor that is indirectly heated by immersion heaters and fluidized with a suitable gas. Indirect heating with immersion heaters provides sufficient heat transfer to the bed while maintaining heater tube temperatures low enough to preclude formation of molten eutectic salts. This is to enable high throughput without the use of air or oxygen injection in the bed, so as to maintain a highly reducing atmosphere. Indirect heating and no partial oxidation are essential features of the TWR/MTCI process. The bench-scale test unit referred to in this report was heated solely by externally-mounted, radiant heaters. No immersion heaters were required for this relatively small test unit.

The bench-scale steam reformer reactor was operated at negative gage pressure to minimize the potential for harmful substance leakage into the work area and to be consistent with standard practices in the nuclear industry for control of radiological contamination. Water and nitric acid in the feed rapidly vaporized in the reactor. Nitrates largely thermally decomposed to $\mathrm{NO}_{\mathrm{x}}$ species. Organic process additives volatilized and pyrolyzed, producing gaseous pyrolysis products and solid-phase char. The gaseous pyrolysis products were further cracked by high-temperature steam and partially reformed to produce lower molecular weight hydrocarbon species, $\mathrm{H}_{2}$, and aromatic compounds. The char, retained in the bed or entrained with fines carried into the off-gas system, was reformed more slowly than the gaseous species to form carbon monoxide and hydrogen. The $\mathrm{CO}, \mathrm{H}_{2}$, low molecular weight hydrocarbons, and char reacted with nitrates, nitric acid, and $\mathrm{NO}_{\mathrm{x}}$, which were reduced to $\mathrm{N}_{2}$. Dissolved inorganic solids in the feed were largely converted to inorganic compounds and salts. Off-gases were routed through a cyclone and a filter to remove the bulk of the entrained product and elutriated carbon fines. A simplified process flow diagram is shown in Figure 1. 
The bed medium was an inert and attrition resistant material (see Proprietary Addendum 1) and the bed was nominally held at a temperature of $580^{\circ} \mathrm{C}$ for the duration of the demonstration. The organic process additives included a liquid additive and a solid reductant. The liquid additive was blended with the SBW stimulant. Solid reductant was added separately to the fluidized bed. These compounds provided the reducing conditions and reactants needed to reduce nitrates/nitrites in the simulant and $\mathrm{NO}_{\mathrm{x}}$ in the offgas to elemental nitrogen. The reaction pathway is given in Proprietary Addendum 1.

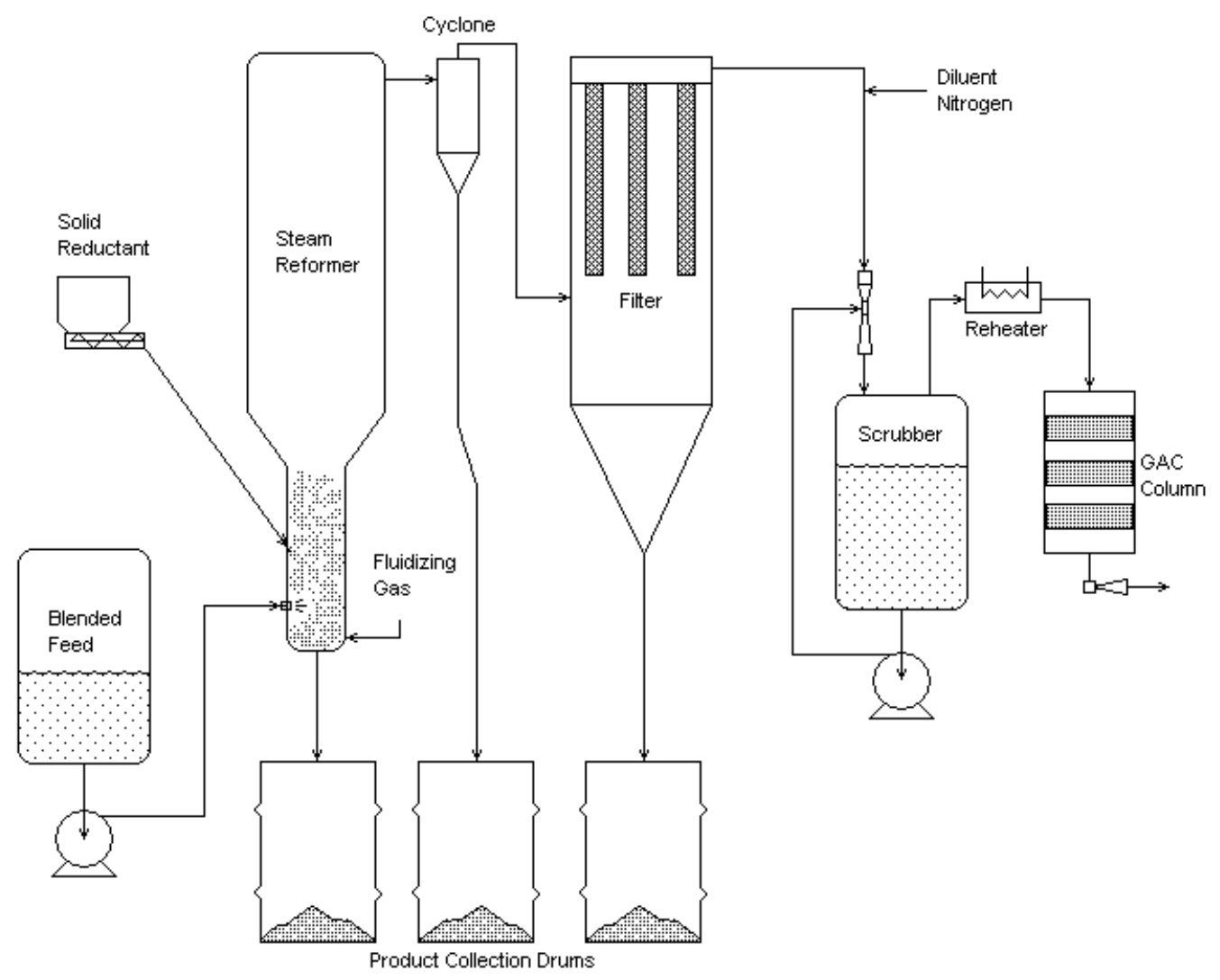

Figure 1. Steam reforming process flow diagram.

The reducing environment provided by organic compounds fed to the fluidized bed also helps minimize the potential for particle agglomeration and enhance radiant heat transfer into the bed as the bed media darken.

As the feed coats the bed particles, it dries and denitrates to form a friable product, most of which subsequently abrades or spalls off the bed particles. The product fines was an ash-like powder that elutriated from the fluidized bed and collected in cyclone or filter vessels. Product was harvested from the process below the cyclone and filter vessel, where the product was collected in 30-gallon product drums. A total of $44 \mathrm{~kg}$ of bed medium were charged to the reactor and $57 \mathrm{~kg}$ were recovered after the end of the demonstration. It is evident that some product accumulates within the bed and may necessitate periodic discharge of some bed material. A test of a longer duration would be instrumental in determining whether 
the product would continue to accumulate on the medium or reach a steady state inventory. Changes in the distributor and atomizing gas velocities could also be made to increase product attrition.

\subsection{Process Equipment Description}

This section describes the six-inch diameter steam reforming test unit used in the demonstration. A more detailed description is available in the test plan (Marshall 2002). Four general categories of equipment including feed systems, the steam reformer, the product collection and solids management systems, and off-gas treatment and waste collection systems are included. All wetted components were constructed from corrosion resistant materials. Equipment and piping were fabricated from 316 stainless steel except for the reformer vessel, which was fabricated from Inconel $800 \mathrm{H}$ and 625.

\subsubsection{Feed Systems}

Feed systems included the simulant hold/makeup tank, two day-tanks, and solid additive feed systems. The simulant tank was designed to hold 800 liters of solution and the day tanks were designed for 200 liters to accommodate feed rates up to eight liters/hr. SBW simulant was transferred to the day tanks, as needed, where it was blended with the liquid additive to formulate the feed for the process.

The feed solution was fed to the reactor by a dual head, peristaltic pump, and metered with a coriolis flow meter. During the optimization and demonstration testing, the feed rate was less than the design basis maximum.

Solid additives were augered from Acrison weight-loss feeders into the process. Shuttle valves and inert gas purges provided isolation of the process to minimize air encroachment into the process, which operated under sub-atmospheric conditions. The bed media had sufficient density that it subsided into the fluidized bed without further assistance, but the solid reductant was pneumatically injected to ensure that bed media was displaced out of the addition line and that the reductant was dispensed directly into the bed.

\subsubsection{Bench-Scale Reformer Description}

The reformer vessel has a bed section that was six inches in diameter and 30 inches tall, mounted below a freeboard section 12 inches in diameter and five feet tall. The two sections were coupled with a concentric $12 \times 6$-inch reducer. Both the bed and freeboard sections were externally heated with heaters designed to fit the contour of the vessel and fit between the penetrations. The reformer has an open or live bottom distributor to allow bed and agglomerates to be discharged from the reactor as needed.

Product fines and process gases exited the freeboard section and passed through a 5-inch diameter cyclone separator to remove most of the particles in excess of $15 \mu \mathrm{m}$. The off-gas was subsequently filtered in a vessel with seven 2.5-inch diameter, 24-inch long, sintered-metal filters with a nominal pore size of $2 \mu \mathrm{m}$.

Product collection equipment temperatures were established to minimize carryover of cesium and rhenium while maximizing mercury carryover. The intent was to operate the cyclone at $500^{\circ} \mathrm{C}$ and the filter vessel at $400^{\circ} \mathrm{C}$. Heat losses between the reformer and the cyclone were less than expected, which caused the cyclone to operate at a higher temperature $\left(540^{\circ} \mathrm{C}\right)$, even after some insulation had been removed. The filter vessel temperature was maintained at $403^{\circ} \mathrm{C}$. 


\subsubsection{Off-Gas Treatment and Waste Collection}

Off-gas handling equipment was installed to quench the off-gas, sorb acidic gases, and capture volatilized mercury. The equipment was provided to accumulate data on the destiny and speciation of offgas constituents. A venturi scrubber was used to scrub out acid gases and to quench the off-gas. The scrub temperature was controlled with an integral heat exchanger to achieve water neutrality (i.e., minimal net water condensation or evaporation).

A continuous emissions monitoring (CEM) system was installed to measure the concentrations of hydrogen, oxygen, carbon dioxide, carbon monoxide, nitrogen oxide, nitrogen dioxide, and methane in the effluent. Because the CEM requires a dry gas (which concentrated the amount of $\mathrm{H}_{2}$ in the off-gas) and because the hydrogen monitor was ranged for 0 to $5 \% \mathrm{H}_{2}$, a nitrogen dilution system was installed. The nitrogen dilution was controlled by a critical orifice that maintains a constant flow of nitrogen dilution gas, regardless of the off-gas line pressure downstream of the orifice. The nitrogen reduced the absolute humidity of the off-gas and ensured that the dry-basis hydrogen concentration was within the range of the instrument. The nitrogen dilution system diluted the entire off-gas and not only a slipstream going to the CEM.

Following the scrubber, the off-gas is reheated to approximately $120^{\circ} \mathrm{C}$ before passing through a granular activated-carbon (GAC) bed. The GAC column was fabricated from 8 -inch diameter schedule 40 pipe and segregated into three sections using internal trays, each holding $1.00 \mathrm{~kg}$ of GAC. With an average bulk density of the GAC being $0.508 \mathrm{~g} / \mathrm{cc}$, the GAC layer was 2.5 inches deep on each tray. The GAC column was externally heated with a heat tape to maintain the column temperature around $122^{\circ} \mathrm{C}$. The GAC was impregnated with sulfur to amalgamate with the mercury vapors that were sorbed from the off-gas.

The air eductor jet served as the vacuum and pumping source for the off-gas. It quickly dilutes the off-gas to the lower dew point and reduces flammable gas concentrations without any mechanical parts that could become an ignition source. The vacuum was controlled by motive gas inlet pressure and drawing bleed air into the vessel off-gas line.

\subsubsection{Data Acquisition and Control System}

The process control functions used Rockwell hardware and software to monitor and control operation of the process from two PC-compatible operator workstations located in the vicinity of the process equipment. An additional process monitoring workstation was located in an office area for nonoperational personnel. The process control functions included automated valve and pump sequences for the feed system, automated control of the fluidizing gas flow rate, selectable input temperature control for the reformer vessel, and vacuum control of the system based on the pressure in the reformer. The graphical user interface (GUI) for the system showed the status of the components, provided a control interface for the operator and displayed readings from all of the instrumentation in numeric and trend form.

The data acquisition system utilized Rockwell software integrated with the control system, and a Sequel database for archiving the data generated. Each record in the database included the tag name for the data-point, the value, and a time-stamp. Analog values from the system were archived once per second and discrete values were archived on change of state. A workstation with a web interface to the database was provided in the office area for access to the archived data during the tests. The web interface provided data, accessed from the database, and averaged at user defined intervals in a Microsoft Excel spreadsheet. 


\section{CONTINUOUS EMISSIONS MONITORING SYSTEM}

\subsection{CEMS Description and Operation}

The continuous emissions monitoring system (CEMS) is shown in Figure 2. A heated sample probe was used to continuously extract a portion of the off-gas from the off-gas pipe. A heated filter at the back end of the heated probe was used to remove particulate matter from the sample gas. The sample gas flowed under negative pressure from the probe through a heated stainless steel sample line to the sample conditioning system. The sample conditioning system included an ice bath chiller followed by a refrigerated chiller to cool the sample gas, condense water from the sample gas, and separate the condensate from the sample gas. Undesired scrubbing of $\mathrm{NO}$ and $\mathrm{NO}_{2}$ in the sample conditioner was minimized by separating the condensate from the sample gas soon after it condensed. The $\mathrm{NO}_{\mathrm{x}}$ analyzers do not detect any $\mathrm{NO}_{\mathrm{x}}$ that was scrubbed from the sample gas.

The sample conditioning system was located in the CEMS upstream of the sample pump so the sample pump (and all valves, flow meters, fittings, and connecting tubing) downstream of the chillers need not be heated. A moisture sensor and backup filter were located immediately downstream of the chillers. The moisture sensor provided alarms (and automatic sample pump shut-off, if the shut-off was enabled) if any liquid water droplets remained in the sample gas or were formed in the sample lines downstream of the chillers. The backup filter provided added protection for the flow meters and analyzers from particulate matter damage or fouling.

The sample pump, downstream of the backup filter, draws sample gas under negative pressure from the off-gas pipe through the probe, heated filter, sample line, chillers, and backup filter. The sample gas was under positive pressure downstream of the sample pump. The components of the sample pump, and all other components of the CEMS that contact the sample gas, were constructed of stainless steel, Teflon, glass, or other materials designed to avoid reaction with the sample gas.

Gas analyzers were used to detect $\mathrm{O}_{2}, \mathrm{CO}_{2}, \mathrm{CO}, \mathrm{NO}, \mathrm{NO}_{\mathrm{x}}, \mathrm{H}_{2}$, and $\mathrm{CH}_{4}$. Specifications of these analyzers are shown in Table 1. The sample gas was split and delivered through rotameters and flow control valves to each analyzer. The sample gas for the $\mathrm{NO}_{\mathrm{x}}$ analyzers was diluted with air at a nominal ratio of three parts air to one part sample gas.

\subsection{Off-gas Measurement Accuracy, Calibrations, and Quality Assurance Checks}

The CEMS was operated according to vendor operating instructions and relevant Environmental Protection Agency (EPA) methods. The analyzers were operated in a dry, cool mode rather than a hot, wet mode. The sample conditioning system was operated consistent with guidance in EPA 2002 to minimize acid gas $\left(\mathrm{SO}_{2}, \mathrm{NO}_{\mathrm{x}}\right.$, etc.) scrubbing. Any higher boiling point compounds like high molecular weight hydrocarbons, if present in the sample gas, may be condensed with water in the chiller system. A separate, odorous condensate phase was observed in the condensate traps of the chillers, evidence that some hydrocarbon material did condense in the chillers. A gas cleanup configuration that includes a thermal oxidizer would destroy the hydrocarbons and ameliorate the buildup of a separate phase. 


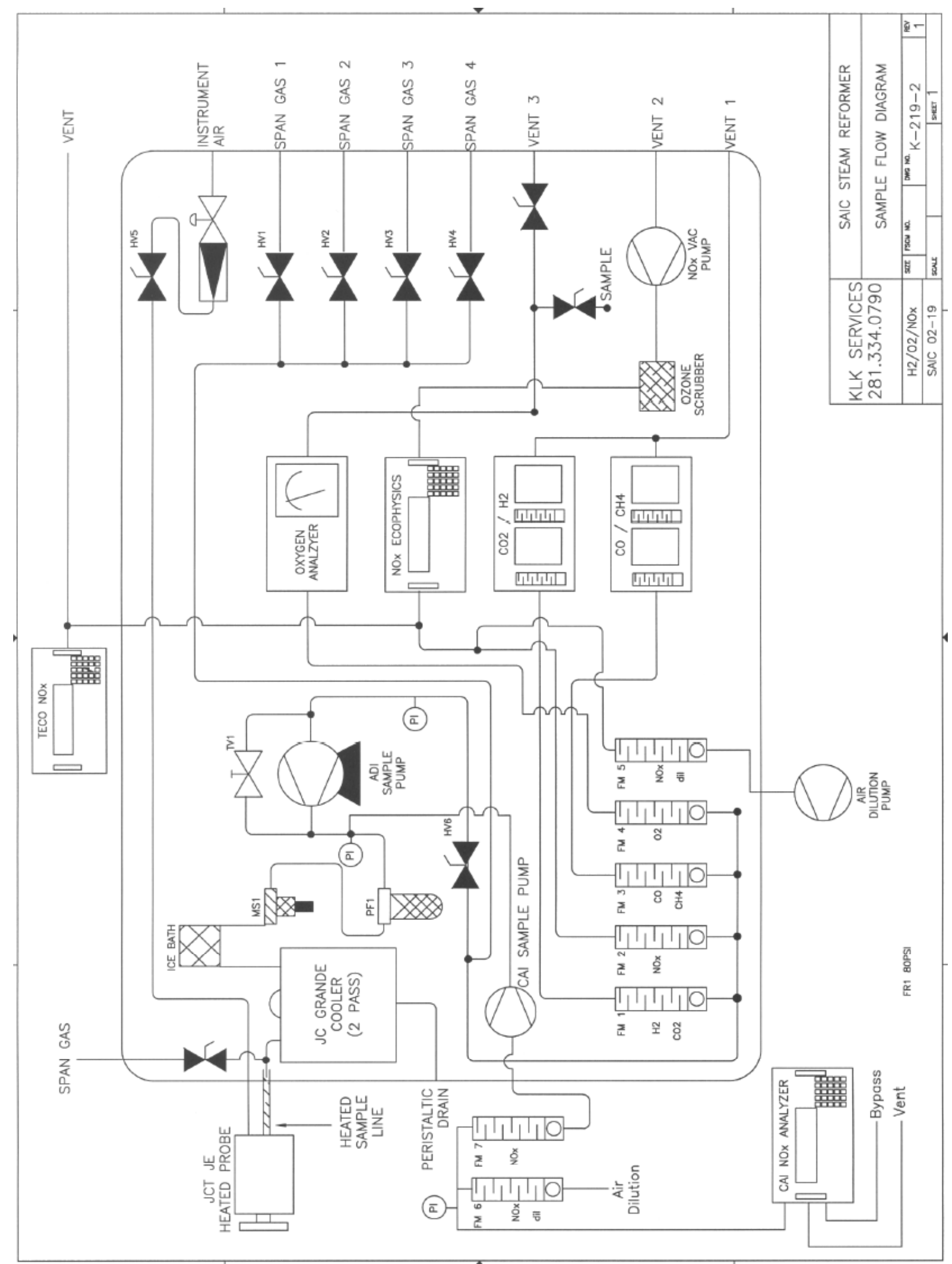

Figure 2. Continuous emissions monitoring system used during the TWR steam reformer 100-hr test. 
Table 1. Analyzers used in the CEMS.

\begin{tabular}{|c|c|c|c|c|c|c|c|c|}
\hline \multirow{2}{*}{$\begin{array}{c}\text { Gas } \\
\text { species }\end{array}$} & \multirow[b]{2}{*}{ Instrument } & \multirow[b]{2}{*}{ Detection principle } & \multirow{2}{*}{$\begin{array}{l}\text { Instrument } \\
\text { range }\end{array}$} & \multicolumn{4}{|c|}{ Acceptance limits, \% FS } & \multirow{2}{*}{$\begin{array}{l}\text { Reference } \\
\text { method }\end{array}$} \\
\hline & & & & Calibration & Drift & Linearity & Bias & \\
\hline $\mathrm{O}_{2}$ & Servomex 1440 & Paramagnetism & $\begin{array}{l}0 \text { to } 25 \% \\
0 \text { to } 100 \%\end{array}$ & \multirow[t]{2}{*}{2} & \multirow[t]{2}{*}{3} & \multirow[t]{2}{*}{4} & \multirow[t]{2}{*}{5} & \multirow{2}{*}{$\begin{array}{c}40 \text { CFR } 60 \\
\text { App. A } \\
\text { Method 3A }\end{array}$} \\
\hline $\mathrm{CO}_{2}$ & \multirow[t]{2}{*}{$\begin{array}{c}\text { Nova } \\
4230 \mathrm{RM}\end{array}$} & $\begin{array}{l}\text { Nondispersive } \\
\text { infrared (NDIR) }\end{array}$ & $\begin{array}{l}0 \text { to } 40 \% \\
0 \text { to } 100 \%\end{array}$ & & & & & \\
\hline $\mathrm{H}_{2}$ & & Thermal conductivity & 0 to $5 \%$ & --- & --- & --- & --- & --- \\
\hline $\mathrm{CO}$ & \multirow{2}{*}{\begin{tabular}{|c|} 
California \\
Analytical \\
Instruments (CAI) \\
200
\end{tabular}} & \multirow[t]{2}{*}{ NDIR } & $\begin{array}{l}0 \text { to } 1 \% \\
0 \text { to } 2 \%\end{array}$ & 5 & 10 & 2 & --- & $\begin{array}{c}40 \text { CFR } 60 \\
\text { App. A } \\
\text { Method } 10\end{array}$ \\
\hline $\mathrm{CH}_{4}$ & & & $\begin{array}{l}0 \text { to } 0.5 \% \\
0 \text { to } 1 \%\end{array}$ & --- & --- & --- & --- & --- \\
\hline \multirow[t]{3}{*}{$\mathrm{NO}, \mathrm{NO}_{x}$} & $\begin{array}{c}\text { Ecophysics CLD } \\
70 \mathrm{E}\end{array}$ & \multirow[t]{3}{*}{ Chemiluminescence } & $\begin{array}{c}0 \text { to } 5 \mathrm{ppm} \\
0 \text { to } 5,000 \\
\text { ppm }\end{array}$ & \multirow[t]{3}{*}{2} & \multirow[t]{3}{*}{3} & \multirow[t]{3}{*}{4} & \multirow[t]{3}{*}{5} & \multirow[t]{3}{*}{$\begin{array}{l}40 \text { CFR } 60 \\
\text { App. A } \\
\text { Method 7F }\end{array}$} \\
\hline & \begin{tabular}{|c|} 
Thermo \\
Environmental \\
Instruments Inc. \\
(TECO) $42 \mathrm{C}$ high \\
range \\
\end{tabular} & & $\begin{array}{l}0 \text { to } 4,000 \\
\text { ppm }\end{array}$ & & & & & \\
\hline & CAI 400 CLD & & $\begin{array}{l}0 \text { to } 1,000 \\
\text { ppm }\end{array}$ & & & & & \\
\hline
\end{tabular}

The analyzers were calibrated with EPA protocol or blended, vendor-certified calibration gases before, during, and after the 100-hr test. The analyzers were calibrated daily during the test. During each calibration, the following activities were generally performed:

- $\quad$ The system was leak-checked by checking the response of the $\mathrm{O}_{2}$ analyzer (a significant $\mathrm{O}_{2}$ response would indicate a significant amount of air inleakage in the CEMS upstream of the sample pump)

- Analyzer zero responses were determined using a zero gas (either air for analyzers besides the $\mathrm{O}_{2}$ analyzer or $\mathrm{N}_{2}$ for analyzers including the $\mathrm{O}_{2}$ analyzer)

- $\quad$ Analyzer span responses were determined using a calibration gas with the specified gas concentration

- Interferences of gas species on the detection of other gas species were determined by recording all analyzer responses for each of the calibration gases

- Calibration data generated prior to any analyzer adjustments applied to CEMS data during the time period prior to the calibration; calibration data generated after analyzer adjustments applied to CEMS data during the time period following that calibration 
- For those analyzers which require air dilution for operation (the $\mathrm{NO}_{\mathrm{x}}$ analyzers) the calibration data were used to generate a composite correction factor for both air dilution and span calibration; all $\mathrm{NO}_{\mathrm{x}}$ measurements were corrected using the composite correction factor

- $\quad$ Significant interferences were recorded and used to adjust the CEMS data.

The zero and span calibration data are shown in Proprietary Addendum 2. All of the calibrations were within calibration acceptance limits except for the $\mathrm{CH}_{4}$ and the $\mathrm{NO}_{\mathrm{x}}$ analyzers. The $\mathrm{CH}_{4}$ analyzer experienced increasing zero bias from organic contamination during the $100-\mathrm{hr}$ test. There were no EPA-specified acceptance criteria for the $\mathrm{CH}_{4}$ analyzer, so no correction for this bias was made. Also, a $\mathrm{CH}_{4}$ zero bias correction was unnecessary because the measured $\mathrm{CH}_{4}$ values frequently exceeded the measurement range of $1 \%$ for the $\mathrm{CH}_{4}$ analyzer. While the analyzer responded with measured $\mathrm{CH}_{4}$ levels up to $5 \%$, any measured values above $1 \%$ are estimates of the true values. A zero bias correction for an estimated number was not justified.

The Servomex $\mathrm{O}_{2}$ analyzer worked well. It zero calibrated, span calibrated, and was very stable. Prior to the 100-hr test, the measured $\mathrm{O}_{2}$ levels in the off-gas ranged between 1-2\%, and then dropped to near zero. Since the analyzer had calibrated well, this drop in $\mathrm{O}_{2}$ was thought to be due to an increasingly leak-tight steam reformer and CEM system. Since the $\mathrm{O}_{2}$ analyzer was operated in the 0 to $25 \%$ range in order to calibrate with air and to provide valid data when the analyzer was measuring sample gas with higher $\mathrm{O}_{2}$ concentrations, all measured $\mathrm{O}_{2}$ concentrations below about $1 \%$ (4\% of the full-scale value of $25 \%$ ) were subject to higher (but unquantified) relative error than the EPA-specified calibration error of $\pm 2 \%$. EPA recommends ranging CEMs so that the measured gas concentration is between $30 \%$ and $100 \%$ of the calibrated instrument range, so that the error in the measured $\mathrm{O}_{2}$ concentration is closer to the specified calibration error limit (EPA 2002). Because of the wide desired measurement range for $\mathrm{O}_{2}$ and other gases for this test, compliance with this recommendation was not possible without multiple analyzers, each calibrated in a different range.

The California Analytical Instruments (CAI) CO analyzer worked well. It zero calibrated, span calibrated, and was very stable. CO levels ranged about $0.2 \%$, unavoidably lower on the 0 to $10 \%$ instrument range than recommended by EPA. The $\mathrm{CO}$ calibration gas concentration, at $5 \% \mathrm{CO}$, was adequate for a midrange calibration on the instrument $0-10 \%$ scale, but unavoidably too high for accurate $\mathrm{CO}$ measurements as low as $0.2 \%$. Just like the $\mathrm{O}_{2}$ measurement, the potential error in the $\mathrm{CO}$ measurement is not quantified but could be higher than the EPA specified calibration error of $\pm 5 \%$. Even so, this analyzer provided $\mathrm{CO}$ measurement data of sufficient quality for the test objectives.

The CAI $\mathrm{CO}_{2}$ analyzer and $\mathrm{H}_{2}$ analyzer worked well. Both zero calibrated, span calibrated, and were stable. Refer to Proprietary Addendum 1 for additional details and information. $\mathrm{The}_{2}$ concentration ranged from $0.0 \%$ to $1.4 \%$ (dry, $\mathrm{N}_{2}$-free basis).

\section{3 $\quad \mathrm{NO}_{x}$ Analyzer Performance, Calibrations, and Quality Control}

The most common off-gas $\mathrm{NO}_{\mathrm{x}}$ analysis technique used worldwide for several decades is based on chemiluminescence of $\mathrm{NO}$ when it forms, with reaction with ozone $\left(\mathrm{O}_{3}\right), \mathrm{NO}_{2}$. A portion of the $\mathrm{NO}_{2}$ formed via this reaction is an unstable radical $\mathrm{NO}_{2}{ }^{*}$ that gives off energy (chemiluminesces) when it converts to $\mathrm{NO}_{2}$. The amount of chemiluminescent discharge is proportional to the concentration of $\mathrm{NO}$ in the sample gas, and can be detected and recorded. Chemiluminescent analyzers designed to detect not only $\mathrm{NO}$ but also total $\mathrm{NO}$ and $\mathrm{NO}_{2}$ include a catalytic $\mathrm{NO}_{\mathrm{x}}$ converter through which the sample gas passes prior to reaction with $\mathrm{O}_{3}$ and chemiluminescent detection. Any $\mathrm{NO}_{2}$ in the sample is converted to $\mathrm{NO}$ in the $\mathrm{NO}_{\mathrm{x}}$ converter, because the $\mathrm{NO}_{2}$ could only be detected if it was first converted to $\mathrm{NO}$, so it could then react with $\mathrm{O}_{3}$ to form the chemiluminescent $\mathrm{NO}_{2}{ }^{*}$ radical. Most chemiluminescent analyzers 
are now configured to measure $\mathrm{NO}$ only, by bypassing the $\mathrm{NO}_{\mathrm{x}}$ converter, and also measure total $\mathrm{NO}$ and $\mathrm{NO}_{2}$ as $\mathrm{NO}_{\mathrm{x}}$ by flowing sample gas through the $\mathrm{NO}_{\mathrm{x}}$ converter. Different analyzer models are made to switch either manually or automatically between the $\mathrm{NO}$ and total $\mathrm{NO}_{\mathrm{x}}$ modes. The difference between the $\mathrm{NO}$ and $\mathrm{NO}_{\mathrm{x}}$ signals is the $\mathrm{NO}_{2}$ value.

The $\mathrm{NO}_{\mathrm{x}}$ analyzers used for the 100-hr test were chemiluminescent analyzers designed in this way. While these analyzers are reliably and commonly used for combustion gas $\mathrm{NO}_{\mathrm{x}}$ analysis, several quality control checks and modifications were made in order to obtain reliable $\mathrm{NO}_{\mathrm{x}}$ measurements with these analyzers from the steam reformer gas. Potential problems in using these analyzers to measure $\mathrm{NO}_{\mathrm{x}}$ in the steam reformer off-gas, and their resolution for the 100-hr test, are summarized below.

\subsubsection{Potential Problems and Resolutions}

The sample gas to the $\mathrm{NO}_{\mathrm{x}}$ analyzers was diluted with air to:

A. Lower the $\mathrm{NO}_{\mathrm{x}}$ values for more accurate measurement within the analyzer range

B. Dilute levels of gas species such as $\mathrm{CO}_{2}, \mathrm{CO}, \mathrm{CH}_{4}$, and $\mathrm{H}_{2}$ that could interfere with the $\mathrm{NO}$ or $\mathrm{NO}_{\mathrm{x}}$ measurements

C. Lower the heating value of the sample gas to prevent high temperatures in the $\mathrm{NO}_{\mathrm{x}}$ converter

D. Provide an excess of $\mathrm{O}_{2}$ in the sample gas compared to the $\mathrm{CO}, \mathrm{CH}_{4}$, and $\mathrm{H}_{2}$ levels, to prevent poisoning of the $\mathrm{NO}_{\mathrm{x}}$ converter catalyst.

The gas species $\mathrm{CO}_{2}, \mathrm{CO}, \mathrm{CH}_{4}$, and $\mathrm{H}_{2}$ interfere with chemiluminescent $\mathrm{NO}_{\mathrm{x}}$ analysis in different ways. For example, $\mathrm{CO}_{2}$ can quench the chemiluminescent signal, causing a negative bias on both NO and $\mathrm{NO}_{\mathrm{x}}$ measurements. This bias was minimized for the 100 -hr test by sample gas dilution with air.

High levels of reduced gas species including $\mathrm{CO}, \mathrm{CH}_{4}$, and $\mathrm{H}_{2}$ will poison the stainless steel $\mathrm{NO}_{\mathrm{x}}$ converter catalyst, causing a failure of the analyzer to detect $\mathrm{NO}_{\mathrm{x}}$ concentrations, if present, higher than the NO concentration. Initial tests prior to the 100-hr test showed that, in fact, straight sample gas with essentially no $\mathrm{O}_{2}$ and typical steam reformer off-gas levels of $\mathrm{CO}, \mathrm{H}_{2}$, and $\mathrm{CH}_{4}$ rapidly (in one hour or less) poisoned the $\mathrm{NO}_{\mathrm{x}}$ converters in both the Ecophysics and Thermo Environmental Instruments, Inc. (TECO) analyzers. This poisoning occurs when the reduced gas species such as $\mathrm{CO}, \mathrm{H}_{2}$, and $\mathrm{CH}_{4}$ reacted with the oxide layer that was the catalyst on the stainless steel $\mathrm{NO}_{\mathrm{x}}$ converter surface. These reactions readily occur at the normal $600^{\circ} \mathrm{C}$ operating temperature for stainless steel $\mathrm{NO}_{\mathrm{x}}$ converters.

These converter-deactivating reactions are prevented when excess $\mathrm{O}_{2}$ is available in the sample gas that flows through the $\mathrm{NO}_{\mathrm{x}}$ converter that provides sufficient oxygen for reaction with the $\mathrm{CO}, \mathrm{H}_{2}$, and $\mathrm{CH}_{4}$ without involving oxygen in the stainless steel oxide layer. The design air dilution factor for the $\mathrm{NO}_{\mathrm{x}}$ analyzers was about $4: 1$, providing at least $5 \% \mathrm{O}_{2}$ in the sample gas to prevent poisoning of the stainless steel $\mathrm{NO}_{\mathrm{x}}$ converter catalyst. After the oxide layer was depleted in the $\mathrm{NO}_{\mathrm{x}}$ analyzers prior to the 100-hr test, operation of the $\mathrm{NO}_{x}$ converters with the air-diluted sample gas flow that included excess $\mathrm{O}_{2}$ readily regenerated the oxide (catalyst) layer.

The $\mathrm{NO}_{\mathrm{x}}$ analyzers all had a composite span calibration/air dilution correction factor, which all $\mathrm{NO}_{\mathrm{x}}$ data were adjusted by. The exact composite dilution/span calibration factor was determined by calibrations performed through the dilution system. The composite correction factor varied from 2.95 to 4.89 for the different calibration periods and different analyzers in both the $\mathrm{NO}$ and $\mathrm{NO}_{\mathrm{x}}$ modes. The 
dilution factor was also corrected for the difference in flow rates of the calibration gases and sample gas based on the different molecular weights of the calibration gases and sample gas.

Even with the air dilution, the Ecophysics and the TECO analyzers each exhibited both a constant positive bias in both the $\mathrm{NO}$ and $\mathrm{NO}_{\mathrm{x}}$ modes, and a short-term positive bias or memory in the $\mathrm{NO}_{\mathrm{x}}$ mode that do not appear in the calibration table shown in Proprietary Addendum 2. The constant $\mathrm{NO}$ and $\mathrm{NO}_{\mathrm{x}}$ bias was indicated by higher average $\mathrm{NO}$ and $\mathrm{NO}_{\mathrm{x}}$ values during sampling for the Ecophysics and TECO analyzers compared to the CAI analyzer. The short-term memory bias was apparent immediately when the sample system was switched from sample gas to zero gas. On zero gas, when the NO response for these analyzers ranged around $0 \mathrm{ppm}$, the $\mathrm{NO}_{\mathrm{x}}$ response ranged around $100 \mathrm{ppm}$ for the Ecophysics analyzer and $70 \mathrm{ppm}$ for the TECO analyzer. Given enough time, the zero gas purged the $\mathrm{NO}_{\mathrm{x}}$ converter to lower the $\mathrm{NO}_{\mathrm{x}}$ responses for these analyzers to approximately zero.

These two positive biases were due to the presence of other gas species in the steam reformer off-gas that were detected by these analyzers as total $\mathrm{NO}_{\mathrm{x}}$. These gases could include other $\mathrm{N}_{\mathrm{x}} \mathrm{O}_{\mathrm{y}}$ species such as $\mathrm{N}_{2} \mathrm{O}, \mathrm{HNO}_{3}$, or $\mathrm{NH}_{3}$, if these species were present in the gas and converted along with $\mathrm{NO}_{2}$ to $\mathrm{NO}$ in the $\mathrm{NO}_{\mathrm{x}}$ converter. Other gas species such as hydrocarbon species can also chemiluminesce and be detected as $\mathrm{NO}_{\mathrm{x}}$ (Summers 1976) in either the $\mathrm{NO}$ or $\mathrm{NO}_{\mathrm{x}}$ modes. $\mathrm{CO}, \mathrm{CH}_{4}$, and other hydrocarbon species can also emit infrared radiation, which can be detected by the detector, after being heated to $600^{\circ} \mathrm{C}$ in the stainless steel $\mathrm{NO}_{\mathrm{x}}$ converters. These two biases were not apparent for the $\mathrm{CAI} \mathrm{NO}_{\mathrm{x}}$ analyzer in either the $\mathrm{NO}$ or $\mathrm{NO}_{\mathrm{x}}$ mode.

The CAI analyzer differs from the other two $\mathrm{NO}_{\mathrm{x}}$ analyzers because it uses:

a. A vitreous carbon $\mathrm{NO}_{\mathrm{x}}$ converter that operates at a much lower temperature of about $80^{\circ} \mathrm{C}$ (so other side-reactions such as conversion of $\mathrm{N}_{2} \mathrm{O}, \mathrm{HNO}_{3}$, or $\mathrm{NH}_{3}$ to $\mathrm{NO}$ were minimized)

b. A narrower bandwidth filter on the chemiluminescence detector that better screens out chemiluminescence and infrared radiation from other gas species.

The short-term memory bias was corrected by subtracting the measured amount of the bias from all of the Ecophysics and TECO $\mathrm{NO}_{\mathrm{x}}$ data. The additional constant bias on the Ecophysics and TECO NO and $\mathrm{NO}_{\mathrm{x}}$ data were corrected using a correction factor established when these two analyzers were operated simultaneously with the CAI NO analyzer on the last day of the 100-hr test.

The difference between the measured $\mathrm{NO}$ and $\mathrm{NO}_{\mathrm{x}}$ concentrations is the calculated $\mathrm{NO}_{2}$ concentration. The corrected $\mathrm{NO}_{2}$ concentrations averaged about $30 \mathrm{ppm}$, which was about $4 \%$ of the total $\mathrm{NO}_{\mathrm{x}}$ concentration. Any errors in the measured $\mathrm{NO}$ and $\mathrm{NO}_{\mathrm{x}}$ concentrations were compounded in the difference calculation, causing relatively larger errors in the $\mathrm{NO}_{2}$ concentrations. The errors in the $\mathrm{NO}$ and $\mathrm{NO}_{\mathrm{x}}$ measurements range around $\pm 5 \%$ of the measured $\mathrm{NO}$ or $\mathrm{NO}_{\mathrm{x}}$ values (about $\pm 40 \mathrm{ppm}$ ) a typical percentage error for off-gas measurements based on instrument, sample conditioner, and calibration accuracy. The error in the $\mathrm{NO}_{2}$ measurement, based on partial differential analysis of the propagated errors in the $\mathrm{NO}$ and $\mathrm{NO}_{\mathrm{x}}$ measurements (Holman 1978) was about $\pm 60 \mathrm{ppm}$, or $\pm 200 \%$ of the average $\mathrm{NO}_{2}$ value. Because the propagated error for the $\mathrm{NO}_{2}$ measurement was larger than the value of the $\mathrm{NO}_{2}$ measurement, considerable variation in the $\mathrm{NO}_{2}$ values occurred. Frequently, the value of the $\mathrm{NO}_{2}$ concentration was negative. These negative values were included in the time-averaging calculations in order to avoid biasing the average $\mathrm{NO}_{2}$ values.

Post-test inspections of the analyzers were performed after the 100-hr test. A water-soluble, white powder, thought to be a solid reaction product of $\mathrm{O}_{3}$ and gas species that flowed out of the $\mathrm{NO}_{\mathrm{x}}$ converter, was observed in the Ecophysics analyzer downstream where the $\mathrm{O}_{3}$ was blended with the sample gas and 
also in the detector cell. This may have contributed to readings from the Ecophysics analyzer that were different from the other two analyzers. The use of multiple $\mathrm{NO}_{\mathrm{x}}$ analyzers provided the information needed to determine the most valid $\mathrm{NO}_{\mathrm{x}}$ measurements and provided correction factors to correct biased $\mathrm{NO}_{\mathrm{x}}$ data.

\section{EXPERIMENTAL SETUP \\ 4.1 SBW and Feed Compositions}

For the purposes of this demonstration, a simulated $\mathrm{SBW}^{1}$ was chosen and prepared that is designed to mimic the composition of the waste contained in tank WM-180 at INTEC. Extensive effort has been put into analyzing and characterizing WM-180 SBW and its composition has been the baseline for waste treatment development work in the past. The target and measured simulant compositions are given in Table 2.

Table 2. WM-180 SBW simulant composition.

\begin{tabular}{|c|c|c|}
\hline Analyte & $\begin{array}{c}\text { Target Simulant Composition } \\
(\mu \mathrm{g} / \mathrm{mL})\end{array}$ & $\begin{array}{l}\text { Measured Simulant Composition } \\
(\mu \mathrm{g} / \mathrm{mL})\end{array}$ \\
\hline Acid & 1.01 Normal & 0.845 Normal \\
\hline Aluminum & $1.79 \mathrm{E} 4$ & $1.54 \mathrm{E} 4$ \\
\hline Ammonia & - & 18.3 \\
\hline Boron & 133 & 61.8 \\
\hline Cadmium & - & $7.9 \mathrm{E}-2$ \\
\hline Calcium & $1.89 \mathrm{E} 3$ & $1.67 \mathrm{E} 3$ \\
\hline Cesium & 852 & 815 \\
\hline Chloride & $1.06 \mathrm{E} 3$ & $1.35 \mathrm{E} 3$ \\
\hline Chromium & 174 & 163 \\
\hline Fluoride & 901 & 291 \\
\hline Iron & $1.21 \mathrm{E} 3$ & $1.15 \mathrm{E} 3$ \\
\hline Lead & 271 & 251 \\
\hline Magnesium & 292 & 322 \\
\hline Manganese & 775 & 456 \\
\hline Mercury & 405 & 458 \\
\hline Nickel & 86 & 80.0 \\
\hline
\end{tabular}


Table 2. (continued).

\begin{tabular}{|c|c|c|}
\hline Analyte & $\begin{array}{c}\text { Target Simulant Composition } \\
(\mu \mathrm{g} / \mathrm{mL})\end{array}$ & $\begin{array}{l}\text { Measured Simulant Composition } \\
(\mu \mathrm{g} / \mathrm{mL})\end{array}$ \\
\hline Nitrate & $3.27 \mathrm{E} 5$ & $2.82 \mathrm{E} 5$ \\
\hline Nitrite & - & 21.2 \\
\hline Phosphate & $1.30 \mathrm{E} 3$ & 365 \\
\hline Phosphorus & 424 & 387 \\
\hline Potassium & $7.66 \mathrm{E} 3$ & $7.81 \mathrm{E} 3$ \\
\hline Rhenium & 426 & 391 \\
\hline Silicon & - & 11.8 \\
\hline Sodium & $4.74 \mathrm{E} 4$ & $4.30 \mathrm{E} 4$ \\
\hline Sulfate & $6.72 \mathrm{E} 3$ & $7.37 \mathrm{E} 3$ \\
\hline TOC & - & - \\
\hline Zinc & 68.6 & 63.4 \\
\hline Zirconium & - & - \\
\hline Specific Gravity & $1.26(\mathrm{~g} / \mathrm{mL})$ & not measured \\
\hline
\end{tabular}

\subsection{Process Optimization}

During the week of December 2 through December 7, 2002, TWR was given an opportunity to verify that all materials had been received, to observe the operation of the bench-scale steam reforming unit, and to adjust process parameters to establish the flow rates and conditions that would satisfactorily demonstrate its technology. The reformer was operated during the last three days of this period, during which time the SBW simulant/liquid additive feed rate, bed temperature, nozzle atomizing ratio (NAR), and solid reductant addition rate were adjusted in response to process performance. TWR generally felt that the steam-reforming unit was limited on gas residence time and that $\mathrm{NO}_{\mathrm{x}}$ destruction, measured during the process optimization test, was less than what could be expected for a full-scale unit. Consequently, TWR requested that the solid reductant addition rate be twice what would otherwise have been added.

Post-test examination of the bed media and the reactor interior showed no fouling or gross accumulation of feed material was visually apparent on the bed particles or the reactor wall. The bed media had darkened to a charcoal-gray color, presumably due to carbon residues. There was some accumulation on the feed nozzle, forming a conical deposit that readily dislodged from the nozzle face. The product catch in the cyclone was a fine black powder with a low bulk density but a significant settling rate in air. The filter solids were black, more cohesive, and easily fluidized mechanically with handling. These solids had a noticeably lower bulk density than the cyclone solids.

\subsection{Technology Demonstration Test Parameters}

For the 100-hr technology demonstration test, the following operating parameters were selected:

- $\quad$ Bed charge was $35 \mathrm{~kg}$ of an inert bed medium

- $\quad$ Operating temperature of $580^{\circ} \mathrm{C}$ 
- $\quad$ Fluidization, feed atomization, and instrument purges using suitable gas(es) specified in Proprietary Addendum 1

- $\quad$ Feed was atomized using a typical NAR with a Spraying Systems Company No. 60100 liquid nozzle and a No. 120 gas cap

- $\quad$ Feed comprised of SBW simulant and a liquid additive

- $\quad$ Feed rate set at the equivalent of $0.9 \mathrm{~L} / \mathrm{hr}$ of SBW simulant

- $\quad$ Solid reductant addition rate as specified in Proprietary Addendum 1.

These parameters were maintained through the $96^{\text {th }}$ hour of operation. At this point, two deviations were permitted to explore impacts on the operation. The first was to elevate the reformer operating pressure from ambient pressure at the distributor to nearly ambient at the outlet of the reformer. The intent was to determine if air infiltration was competing with $\mathrm{NO}_{\mathrm{x}}$ for reducing gases (e.g., hydrogen and carbon monoxide). No observable difference was noted in the composition of the off-gas, indicating that the seals and gaskets were functioning properly and air infiltration was insignificant. Secondly, the solid reductant addition rate was cut in half to observe whether the $\mathrm{NO}_{\mathrm{x}}$ values would rise or stay roughly constant. The intent was to determine if the solid reductant addition rate had been appropriate. The $\mathrm{NO}_{\mathrm{x}}$ values rose only slightly, indicating that the solid reductant addition rate had been higher than necessary for a given $\mathrm{NO}_{\mathrm{x}}$ destruction efficiency.

\section{OBSERVATIONS AND RESULTS}

\subsection{Normal Operations}

The reformer was brought on-line and operated as intended. Thirty-five kg of bed media were charged to the reactor and feed was prepared according to the recipe. Dense bed temperatures were controlled at $\sim 579^{\circ} \mathrm{C}$ with in-bed thermocouple readings within 3-5 degrees of each other, confirming good bed fluidization and the absence of severe agglomeration. The temperature drop between the vessel exterior and the bed slowly decreased from $26^{\circ}$ to $20^{\circ} \mathrm{C}$, indicating an improvement in the heat transfer. This is attributed to improved radiant heat transfer from the shell to the bed as a result of dark product and carbon accumulations on the bed particles. Graphical representations of the temperature profiles and other operating parameters can be found in TWR observations in Proprietary Addendum 3.

The instantaneous solid reductant addition rate fluctuated widely with a small time period as the Acrison weight-loss feeder augured the reductant into the pneumatic injector (a.k.a. shotgun). The reductant fell from the feeder in pulses, as the augur flight swept around the discharge opening, at a frequency that did not coincide with the frequency of the shotgun shuttle valves. This resulted in variations in the charge injected with each cycle of the shotgun. With the shotgun cycling several times each minute, the solid reductant feed rate, over consecutive one-minute periods, varied with standard deviation of $7.4 \%$.

The modified Spraying Systems Company feed spray nozzle worked very well. The nozzle backpressure generally remained constant ( $\sim 5$ psig) and the dense bed temperature distribution stayed uniform throughout the test. This lends support to both the design and the location of the nozzle. TWR, however, would have preferred a floor-mounted nozzle configuration, pointed vertically upwards, with the nozzle exit a few inches above the distributor.

With exception of a couple interruptions in the operation and continuous attention demanded by the CEM as described in the following sections, the run proceeded smoothly. 


\subsection{Off-Normal Operations and Resolutions}

Several operational challenges occurred during the course of the demonstration test, including difficulties operating the CEM, pressure probe plugging, scrub pump failure, and communication failure on the data acquisition system. None of these were a direct result of the process conditions except for interferences with the CEM detectors. Many of the CEM problems were related to the high organic and possible ammonia concentrations in the off-gas, which would have been mitigated or prevented if a thermal oxidation unit had been installed in the off-gas treatment train. The off-gas treatment system was not, however, designed to be representative of a full-scale system and combustible off-gas components were emitted without mitigation.

Two $\mathrm{NO} / \mathrm{NO}_{\mathrm{x}}$ analyzers were used throughout the demonstration run and a third was brought on-line near the end of the run. All three analyzers used chemiluminescence to detect nitrogen oxides; two operating at low pressure and high $\mathrm{NO}_{\mathrm{x}}$ converter temperature and the third with higher pressure and lower temperatures. All three units were designed to analyze combustion gases with residual oxygen and trace quantities of organics and ammonia. The off-gases were rich in organics, as noted by the discoloration of the scrub solution and polymeric tubing, and likely contained measurable concentrations of ammonia that contributed to deposition of suspected ammonium nitrate salts in the analyzer orifices, filters, and optical cells. A consequence of the dirty gases was that the analyzers did not have as good of agreement as hoped. The third instrument brought on-line, from CAI, was expected to have less interference because the converter was operated at higher pressure and lower temperature than the other two analyzers, and because of more complete filtering of interfering light in the reactor cell. Furthermore, the converter was of vitreous carbon rather than a catalytically active metal. This instrument read consistently lower $\mathrm{NO}_{\mathrm{x}}$ levels than the other two instruments, and is believed to provide more representative $\mathrm{NO}_{\mathrm{x}}$ measurements, without potential negative interference from loss of $\mathrm{NO}_{\mathrm{x}}$ converter efficiency, or potential positive interferences from the presence of other gas species such as $\mathrm{NH}_{3}$ and hydrocarbons.

Gas purges were applied to the pressure taps on the reformer vessel to help prevent the probes from plugging. This worked well for most of the probes, but the pressure tap used for bed density measurement (PT4), located 12 inches above the distributor, repeatedly became restricted or plugged. No cause was determined, but it appears to have been due to bed media intrusion in the probe. If so, this problem was due to bed dynamics in the vicinity of the probe and was not a consequence of the process chemistry.

Short interruptions in the test were caused by equipment failures and computer-related problems that were resolved quickly. A failed centrifugal scrub pump was replaced with a diaphragm pump, and the pneumatic additive injector (a.k.a. shotgun) had to be quickly reconfigured when a vent filter broke off of the injector. Neither of these failures were related to the process chemistry.

After problems and equipment failures were resolved/fixed, feed streams to the reformer were restarted and the test resumed.

The 100-hr demonstration test was characterized by safe, stable, and reliable operation with uniform bed temperature distribution, excellent operability, and high availability. There was neither bed agglomeration nor fouling of the reformer internals. The static pressures and the pressure drops generally remained constant during the $100-\mathrm{hr}$ test. The unit seamlessly resumed operation after two feed interruptions; first after a mechanical problem in the solid additive feed line and secondly due to a problem in the firmware of the processor for the programmable logic controller (PLC). With the simulant feed back online after each interruption, all the operating conditions returned to the pre-interruption levels and demonstrated the process recoverability, stability, and ease of operation. 


\subsection{Off-gas Composition}

CEM measurements were performed to determine the off-gas composition of the steam reformer. These measurements were made using an extractive sampling and conditioning system and suite of analyzers to measure for $\mathrm{O}_{2}, \mathrm{CO}_{2}, \mathrm{CO}, \mathrm{NO}, \mathrm{NO}_{\mathrm{x}}, \mathrm{H}_{2}$, and $\mathrm{CH}_{4}$. The sample probe for the CEMS was located downstream of the heated filter vessel, upstream of the venturi scrubber. Nitrogen gas was added to the off-gas just upstream of the CEMS sample probe in order to dilute the off-gas, lowering concentrations of some off-gas species prior to sample extraction and analysis. This dilution lowered the $\mathrm{H}_{2}$ concentration in the sample gas, assuring that the $\mathrm{H}_{2}$ concentration did not pose an explosion or flammability hazard when moisture was removed from the sample gas in the sample conditioner. The $\mathrm{N}_{2}$ dilution also lowered the concentrations of some gas species to be within valid measurement ranges for the analyzers.

The steam reformer off-gas composition is shown in Figures 3 and 4. Additional data is available in Proprietary Addendum 1. These concentrations are reported on a dry basis (after moisture was removed from the sample gas in the sample conditioner) and are also normalized to an $\mathrm{N}_{2}$-free basis. This normalization was done by assuming that the difference between $100 \%$ and the sum of the concentrations of the measured gas species is the concentration of $\mathrm{N}_{2}$ in the off-gas. The normalized values best represent the dry basis steam reformer gas composition, although some gas species, like $\mathrm{HCl}, \mathrm{H}_{2} \mathrm{~S}, \mathrm{SO}_{2}, \mathrm{NH}_{3}$, and total hydrocarbons (THC), that may be present at low concentrations (probably under $0.1 \%$ ), were not measured. The dilution and purge $\mathrm{N}_{2}$ has been subtracted from the off-gas in order to best show the concentrations of measured species without any dilution from $\mathrm{N}_{2}$ used in purges that were vented into the steam reformer system, and without any dilution from $\mathrm{N}_{2}$ added to the steam reformer off-gas at the outlet of the heated filter. The compositions were also corrected for any calibration error, bias, and air dilution used in the CEMS.

The dry, un-normalized, uncorrected, as-measured off-gas composition, calculations, and notes are provided in Proprietary Addendum 2.

The measured $\mathrm{O}_{2}$ content averaged about $0.2 \%$ (dry, corrected for dilution and purge $\mathrm{N}_{2}$ ). In fact, the true steam reformer $\mathrm{O}_{2}$ concentration was probably much closer to $0 \%$. The measured $\mathrm{O}_{2}$ concentration was probably biased higher than the true concentration due to a slight zero calibration error, or because of small amounts of air inleakage at various locations in the steam reformer system or in the CEMS.

System diagnostic tests summarized in Section 4.3 showed that if there was some air inleakage, it was downstream of the high temperature sections (the fluidized bed, the cyclone, and the heated filter), because the measured $\mathrm{H}_{2}$ concentration in the off-gas did not vary as the steam reformer vacuum was changed. 


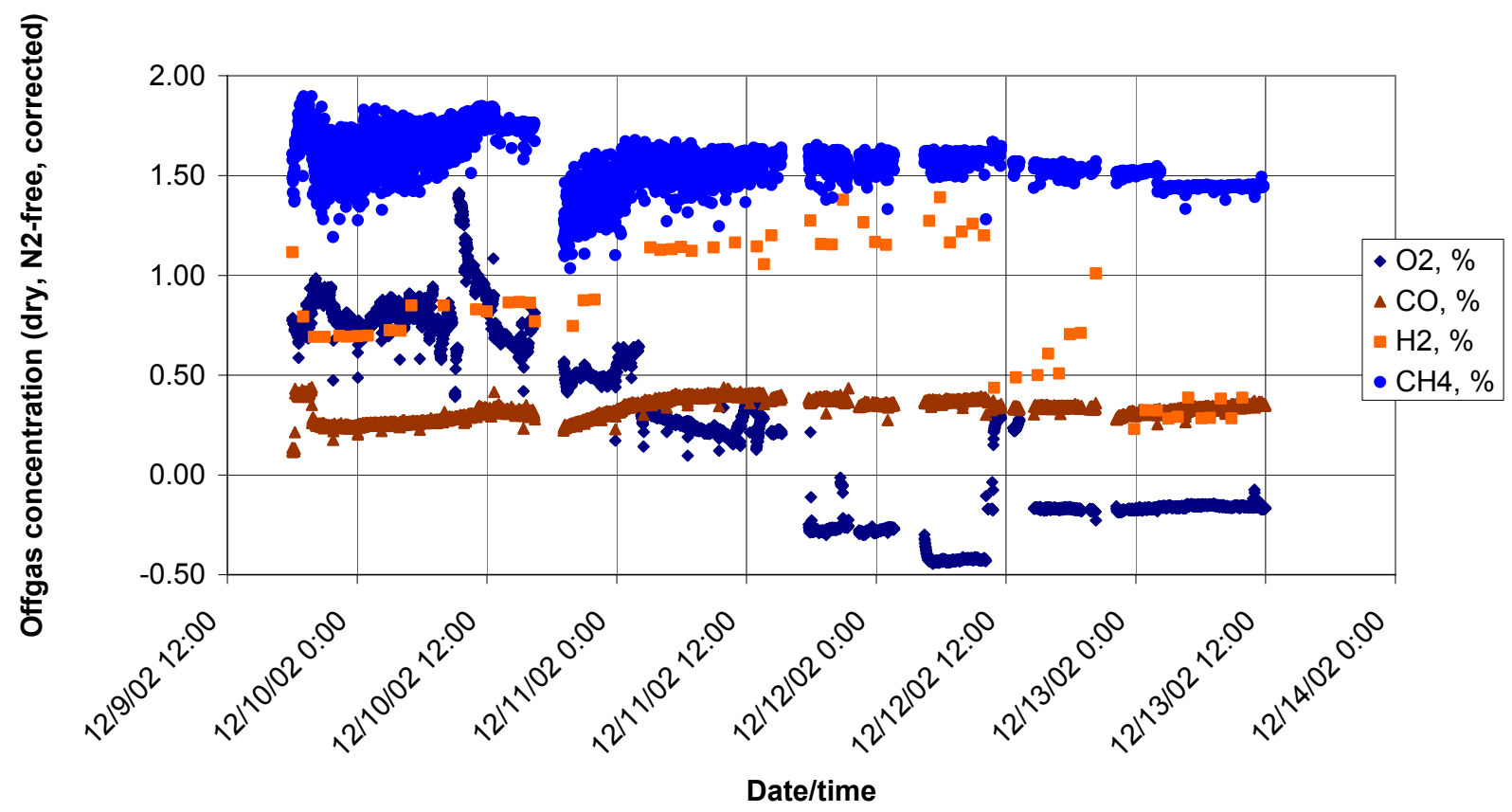

Figure 3. $\mathrm{O}_{2}, \mathrm{CO}, \mathrm{H}_{2}$, and $\mathrm{CH}_{4}$ composition measurements for the TWR steam reformer 100-hr test.

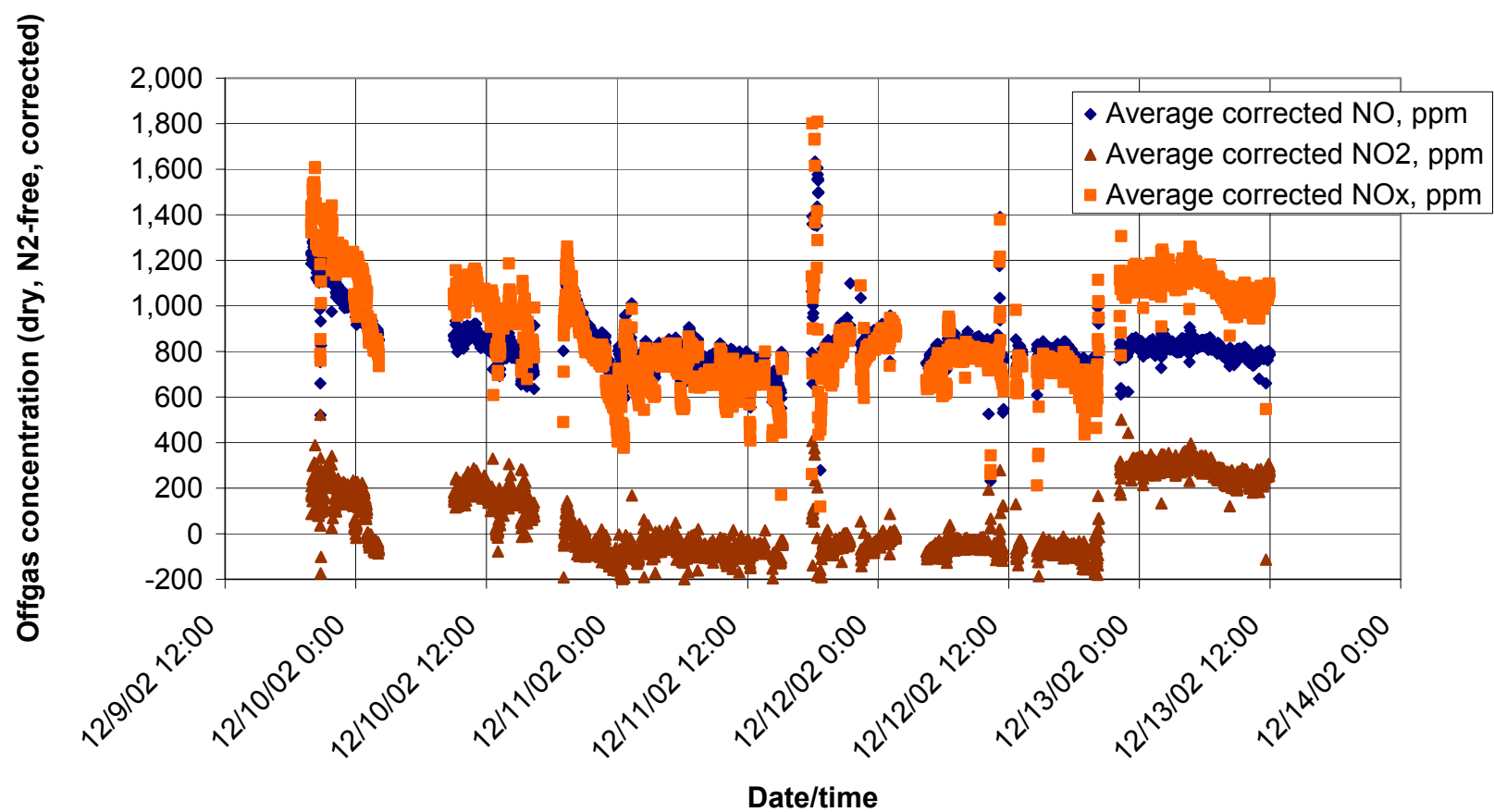

Figure 4. Corrected $\mathrm{NO}_{\mathrm{x}}$ composition measurements for the TWR steam reformer 100-hr test. 
On average, total $\mathrm{CO}$ and $\mathrm{CH}_{4}$ levels in the off-gas ranged about $1.9 \%$. The $\mathrm{CO}$ and $\mathrm{CH}_{4}$ provided the intended reducing conditions in the steam reformer to reduce nitrates in the feed to $\mathrm{N}_{2}$. CO levels averaged $0.3 \%$, while the measured $\mathrm{CH}_{4}$ levels averaged $1.6 \%$.

The $\mathrm{CH}_{4}$ concentrations were much higher than expected by the TWR flowsheet in contrast to the $\mathrm{H}_{2}$ and $\mathrm{CO}$ concentrations that were lower than expected. TWR suggests that the methanation reaction, which combines $\mathrm{CO}$ and $\mathrm{H}_{2}$ to produce $\mathrm{CH}_{4}$, may have contributed significantly to the unexpected $\mathrm{CH}_{4}$, $\mathrm{CO}$ and $\mathrm{H}_{2}$ levels. Incomplete conversion of the organic additives may have possibly been another factor.

The $\mathrm{H}_{2}$ content in the off-gas was low, averaging about $0.8 \%$. This average value was derived from manually recorded hourly readings rather than from the electronically logged data. Manually recorded data were reported instead of electronically logged $\mathrm{H}_{2}$ data because a $0.6 \%$ positive offset was used in the data logger to ensure safe operation was maintained with $\mathrm{H}_{2}$ levels below the $4 \%$ lower flammability limit (LFL in air). The $\mathrm{H}_{2}$ values, when corrected for interferences, ranged from $0.0 \%$ to $1.4 \%$ (dry, $\mathrm{N}_{2}$-free basis).

\section{$5.4 \quad \mathrm{NO}_{\mathrm{x}}$ Concentrations and $\mathrm{NO}_{\mathrm{x}}$ Reduction}

The off-gas $\mathrm{NO}$ and $\mathrm{NO}_{\mathrm{x}}$ concentrations (dry, $\mathrm{N}_{2}$-free basis) averaged about $830 \mathrm{ppm}$ and $860 \mathrm{ppm}$, respectively. These values were based on measured values, corrected for the composite air dilution/span calibration factor determined during calibrations, and also normalized to an $\mathrm{N}_{2}$-free basis. The $\mathrm{NO}$ and $\mathrm{NO}_{\mathrm{x}}$ concentrations were also corrected for measurement variations between three different chemiluminescent analyzers used during the 100-hr test. The instrument corrections are described below and shown in Proprietary Addendum 2.

The reduced gas species $\mathrm{CO}, \mathrm{CH}_{4}, \mathrm{H}_{2}$, intermediate ions including $\mathrm{OH}^{*}$, and intermediate free radicals of these species were present in the steam reformer gas to react with nitrates in the feed and $\mathrm{NO}_{\mathrm{x}}$ gas species that evolved from the feed. These gas species stripped the oxygen from the $\mathrm{NO}_{\mathrm{x}}$ gas species, progressively converting nitrate, $\mathrm{NO}_{2}$, and $\mathrm{NO}$ to $\mathrm{N}_{2}$. Intermediate $\mathrm{NO}_{\mathrm{x}}$ species, like $\mathrm{N}_{2} \mathrm{O}$ and more reduced species like $\mathrm{NH}_{3}$, were not measured. While $\mathrm{NH}_{3}$ was not measured, the odor of $\mathrm{NH}_{3}$ was sensed in scrubber and CEMS condensate solutions.

The degree of $\mathrm{NO}_{\mathrm{x}}$ reduction was calculated based on the $\mathrm{NO}_{\mathrm{x}}$ Maximum Theoretical Emission Concentration (MTEC) and the measured $\mathrm{NO}_{\mathrm{x}}$ concentrations in the steam reformer off-gas. The MTEC was calculated based on the conversion of all nitrate in the feed, regardless of whether the nitrate was in the form of free nitric acid $\left(\mathrm{HNO}_{3}\right)$ or in the form of a metal nitrate, such as $\mathrm{NaNO}_{3}$ or $\mathrm{Al}\left(\mathrm{NO}_{3}\right)_{3}$. The highest possible MTEC from decomposition of nitrate results when one mole of $\mathrm{NO}$ and $\mathrm{NO}_{2}$ (total) was formed from one mole of nitrate. This may occur via any proportions of the following possible decomposition pathways:

$\mathrm{NO}_{3}=\mathrm{NO}+\mathrm{O}_{2}$

$\mathrm{NO}_{3}=\mathrm{NO}_{2}+1 / 2 \mathrm{O}_{2}$

For simplicity, the $\mathrm{H}^{+}$and $\mathrm{M}^{+}$ions are not shown. The MTEC and $\mathrm{NO}_{\mathrm{x}}$ reduction calculations are shown in Proprietary Addendum 2. Because nitrate and nitrite analyses for the simulant and feed were lower than expected, based on the target simulant compositions, the acid normality was added to the nitrate/nitrite results for the purpose of computing nitrate destruction.

The calculated $\mathrm{NO}_{\mathrm{x}}$ reduction is shown in Figure 5. Separate values are shown for NO reduction (based only on the $\mathrm{NO}$ measurement) and total $\mathrm{NO}_{\mathrm{x}}$ reduction (based on the total $\mathrm{NO}_{\mathrm{x}}$ measurement). 
$\mathrm{NO}$ and $\mathrm{NO}_{\mathrm{x}}$ reduction for the entire 100 -hr run averaged $86.6 \%$ and $86.3 \%$, respectively. TWR considers the $\mathrm{NO}_{\mathrm{x}}$ reduction to be very favorable for a single-stage operation. An increase in residence time and reformer temperature may further enhance $\mathrm{NO}_{\mathrm{x}}$ reduction.

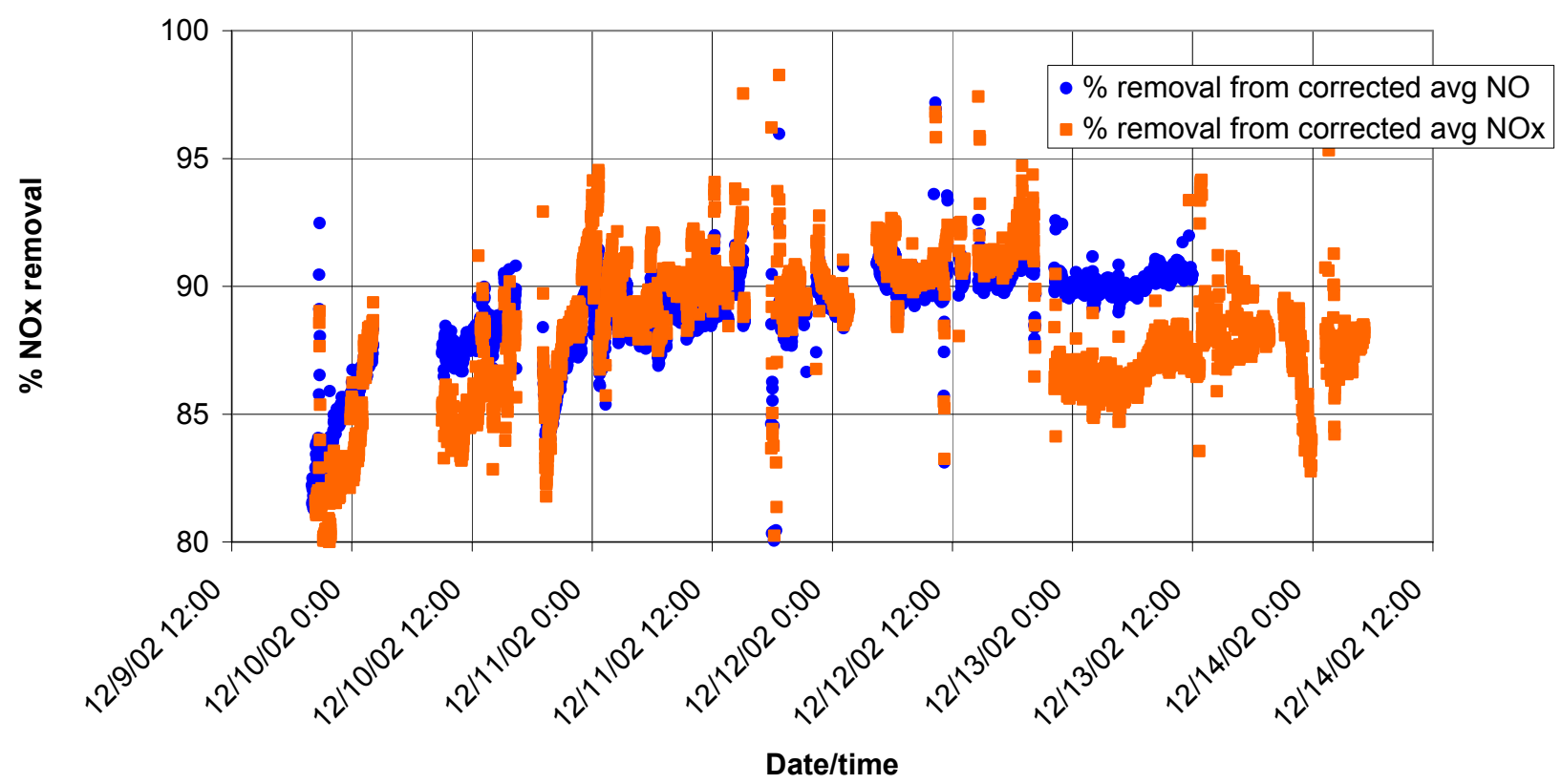

Figure 5. $\mathrm{NO}_{\mathrm{x}}$ reduction for the TWR steam reformer 100-hr test.

\subsection{Process Material Balance}

A process material balance was performed by Eldredge Engineering on the major cations, toxic heavy metals, radionuclide surrogates, and anions of concern. Data were taken from the masses and concentrations of the bed, additives, feed, products, and scrub solution. Of the metals, only mercury showed an accumulation on the GAC bed that contributed significantly to the mass balance. Overall, the mass balance closed very well, especially for the more abundant elements. A significant fraction of the more volatile elements seems to have been lost to the process, as can be seen in Table 3 and Figure 6 . Sulfur recovery in the product and scrub may be under reported. Some of the sulfur may be present as sulfides in the product and, therefore, unaccounted for by sulfate analysis. The GAC was not analyzed for sulfur or chlorine, in part because the GAC is sulfur impregnated to amalgamate with mercury.

Table 3. Mass balance.

\begin{tabular}{lcccr}
\hline \multicolumn{1}{c}{ Component } & In (grams) & Out (grams) & \%Variance & Comments \\
\hline Carbon (reductants) & 132,654 & 134,918 & $1.7 \%$ & Excellent \\
BMC & 30,052 & 29,835 & $-0.7 \%$ & Excellent \\
Sodium & 4,240 & 4,274 & $0.8 \%$ & Excellent \\
Potassium & 745.2 & 671.3 & $-9.9 \%$ & Very Good \\
Sulfur & 190.6 & 119.6 & $-37.2 \%$ & Poor
\end{tabular}


Table 3. (continued).

\begin{tabular}{llccr}
\hline \multicolumn{1}{c}{ Component } & In (grams) & Out (grams) & \%Variance & Comments \\
\hline Calcium & 162.3 & 162.4 & $0.0 \%$ & Excellent \\
Chloride & 113.2 & 77.6 & $-31.4 \%$ & Fair \\
Iron & 108.2 & 112.6 & $4.1 \%$ & Excellent \\
Cesium & 69.2 & 55.8 & $19.3 \%$ & Good \\
Mercury & 41.5 & 5.6 & $-86.5 \%$ & Poor \\
Rhenium & 38.0 & 53.2 & $40.0 \%$ & Poor \\
Phosphorous & 35.8 & 34.8 & $-3.0 \%$ & Excellent \\
Lead & 23.2 & 15.2 & $-34.4 \%$ & Fair \\
Chromium & 15.9 & 17.2 & $8.1 \%$ & Very Good \\
Cadmium & 0.0071 & 0.0068 & $-4.4 \%$ & Excellent \\
\hline \hline & 35,835 & 35,435 & $-1.1 \%$ & Excellent \\
\multicolumn{1}{c}{ (incl. carbon) } & 168,489 & 170,353 & $1.1 \%$ & Excellent \\
\hline
\end{tabular}

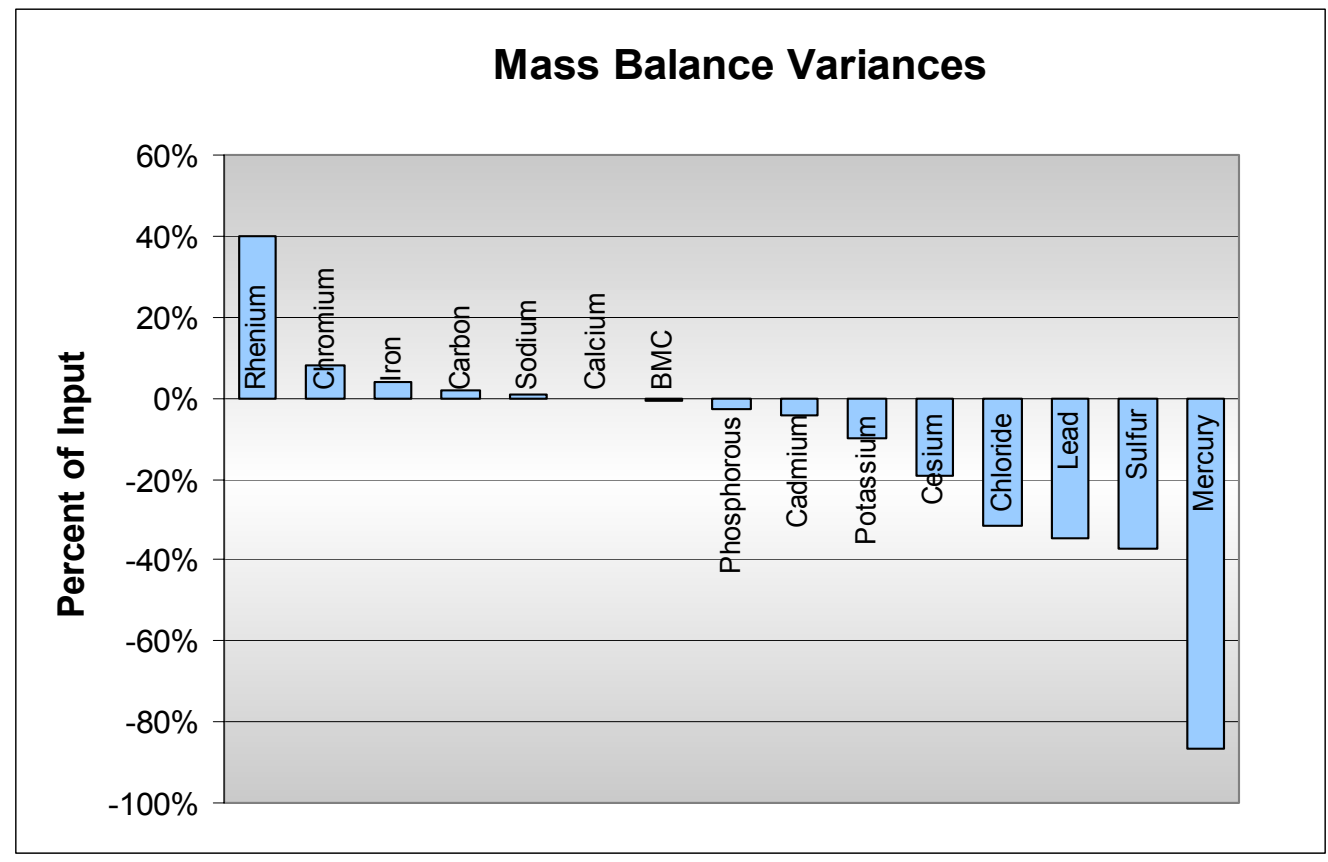

Figure 6. Mass balance variances.

\subsection{Nature and Fate of Mercury}

\subsubsection{Mercury Speciation}

EPA mercury trains were installed and operated to sample the off-gas downstream of the product filter and downstream of the GAC bed. The latter location was sampled only once, near the end of the 
demonstration to ensure that the system had achieved steady-state operation. Two sampling events were completed downstream of the product filter; one mid-way through the demonstration and the other near the end. An aqueous impinger series was used to capture the mercury from the off-gas stream. The first impinger was filled with a potassium chloride solution to capture the oxidized mercury in the off-gas. This was followed by impingers designed to remove elemental mercury; namely, potassium permanganate/sulfuric acid and hydrogen peroxide/nitric acid solutions. The sample results show that over $99 \%$ of the mercury in the off-gas was reduced to elemental mercury.

\subsubsection{Mercury in the Product}

Mercury concentrations in the cyclone product were low, because the product had recently elutriated from the hot reactor and was quickly removed from the off-gas stream. The filter product, however, operated significantly cooler than either the bed or the cyclone $\left(400^{\circ} \mathrm{C}\right.$ vs. $580^{\circ} \mathrm{C}$ in the bed and $530^{\circ} \mathrm{C}$ in the cyclone). The filter product resides as a cake on the filter through which all the off-gas must pass, until dislodged from the filters. This greatly increased the time that the product was exposed to the off-gas stream. Furthermore, the filter product has a higher concentration of elemental carbon, which may sorb more mercury from the off-gas stream, especially at the lower operating temperature. Typical concentrations of mercury in the cyclone product were $3.3 \pm 1.1 \mu \mathrm{g} / \mathrm{g}$ while the filter product had nearly four times the mercury concentration; averaging $12.8 \pm 4.9 \mu \mathrm{g} / \mathrm{g}$.

\subsubsection{Mercury in the Scrub Solution}

Because the mercury was predominately in the elemental state, very little was scrubbed out by the off-gas scrubber. The accumulation was not linear and the concentration appears to be more an inverse function of scrub solution volume than operating time. With one anomalous sample value excluded, the average scrub solution concentration was $2.8 \pm 1.3 \mu \mathrm{g} / \mathrm{L}$.

\subsubsection{Mercury Captured on the Granular Activated Carbon}

Given the nature of the reforming process, with a solid reductant added to the hot reformer bed, it was not surprising that the pyrolysis products would have an impact on the sorption of mercury by the GAC column. The GAC column was segregated into three identical bed sections, each containing $1.00 \mathrm{~kg}$ of sulfur impregnated GAC (manufactured by NUCON International) on each layer averaged $4.8 \%$ with an overall column efficiency of $13.8 \%$.

At the conclusion of the demonstration run, the GAC bed had been on-line for a total of 89.4 hours. The three sections had increased in mass to $1.29,1.28$, and $1.28 \mathrm{~kg}$ (averaging a total sorption capacity of $28.3 \%$ of the original carbon mass) and had absorbed $1.87,1.80$, and 1.68 grams of mercury. The total sorption capacity was consistent with expected total sorption capacities at the relatively high bed operating temperature (Joyce 2003, Soelberg 2003) but the sorption capacity for Hg averaged only $0.178 \%$, much lower than the expected $\mathrm{Hg}$ sorption capacity of at least $10 \%$ for GAC beds in normal operation. During this time period, over 39 grams of mercury had been fed to the process. Based on the quantities of mercury sorbed on each section, the respective sorption efficiencies for each later averaged $4.8 \%$ with an overall column efficiency of $13.8 \%$. This $\mathrm{Hg}$ sorption efficiency was much lower than the expected $\mathrm{Hg}$ sorption efficiency of up to $100 \%$ for GAC beds in normal operation.

The quantities of mercury that were captured by the EPA trains indicate that the GAC column was not sorbing mercury at the end of the demonstration run, but passing $100 \%$ of the mercury vapors. It is believed that the pyrolysis products may have occupied active sites within the activated carbon and condensed in the pores, thus preventing efficient mercury removal. The majority of the total mass increase for the GAC was from sorbed hydrocarbons. A portion of the total weight gain may have been 
from sorption of water from the off-gas. However, at the relatively high operating temperature, the relative humidity of the off-gas was under $20 \%$, which is well under the vendor-recommended humidity limit of $90 \%$.

\subsection{Fate of Cesium and Rhenium}

Cesium and technetium are semi-volatile radionuclides that can become problematic in a thermal treatment process because they can be difficult to retain in the product and tend to mitigate into off-gas system components. There has been some indication that both radionuclides may migrate through a thermal process as cesium pertechnetate, which has a cesium to technetium mole ratio of 1:1. Rhenium was substituted for technetium, as a non-radioactive surrogate, and the concentrations of cesium and rhenium were artificially inflated to test this mechanism of radionuclide migration. The measured cesium and rhenium concentrations in the blended feeds gave a cesium to rhenium mass ratio of $1.82 \mathrm{~g} \mathrm{Cs} / \mathrm{g} \mathrm{Re}$ and a mole ratio of 2.55 mole Cs/mole Re.

A substantial fraction (approximately $70 \%{ }^{2}$ ) of the rhenium in the feed deposited on the bed material, never leaving the bed vessel during the 100-hr test. About $30 \%$ was found in the product fines, and only $0.1 \%$ was recovered in the scrub. While about $81 \%$ of the cesium has been accounted for, only $10 \%$ of the recovered cesium mass was found in the bed, $90 \%$ in the product, and a mere $0.02 \%$ in the scrub. The $\mathrm{Cs} / \mathrm{Re}$ final mass ratios were 1.8 in the feed, 0.2 in the bed, 3.3 in the cyclone product, 4.7 in the filter product, and 0.4 in the scrub solution. It is clear that the cesium was depleted in the bed in product and scrub, relative to rhenium, while being enriched in the elutriated products.

Rhenium emissions to the filtered off-gas increased as the demonstration proceeded and the bed approached a steady state rhenium inventory. Feed to the reformer was interrupted during the scrub pump changeout, but the bed remained at temperature. This would have resulted in a decrease in cesium emissions while the rhenium emissions would have been sustained by the bed inventory. If cesium and rhenium volatized as cesium perrhenate, the mass ratio would be $0.71 \mathrm{~g} \mathrm{Cs} / \mathrm{g} \mathrm{Re}$ in the scrub. The mass ratio, indeed started near 0.7 , but decreased with time, indicating an increase in rhenium relative to cesium as the demonstration continued. Perrhenate salts are known to be strong oxidizers and rhenium metal has been produced by hydrogen reduction of perrhenates, so it is likely that they are reduced in the reformer to rhenium dioxide or rhenium metal. Both of these reduced species have melting points well in excess of the process temperatures and would exist only as a solid. The majority of the rhenium was encapsulated in the product phases, but some may have been entrained as very fine particles. The general trend toward a lower Cs:Re mass ratio and the step change related to the scrub pump failure/change out can be seen in Figure 7. The values have been corrected for the background Cs concentration in the virgin scrub solution.

\footnotetext{
${ }^{2}$ The measured quantity of rhenium that remained in the bed exceeded the quantity in the feed and virgin bed material. The value of approximately $70 \%$ retention on the bed was achieved by the difference of what was fed to the process and what was accounted for in the product fines and scrub solution.
} 


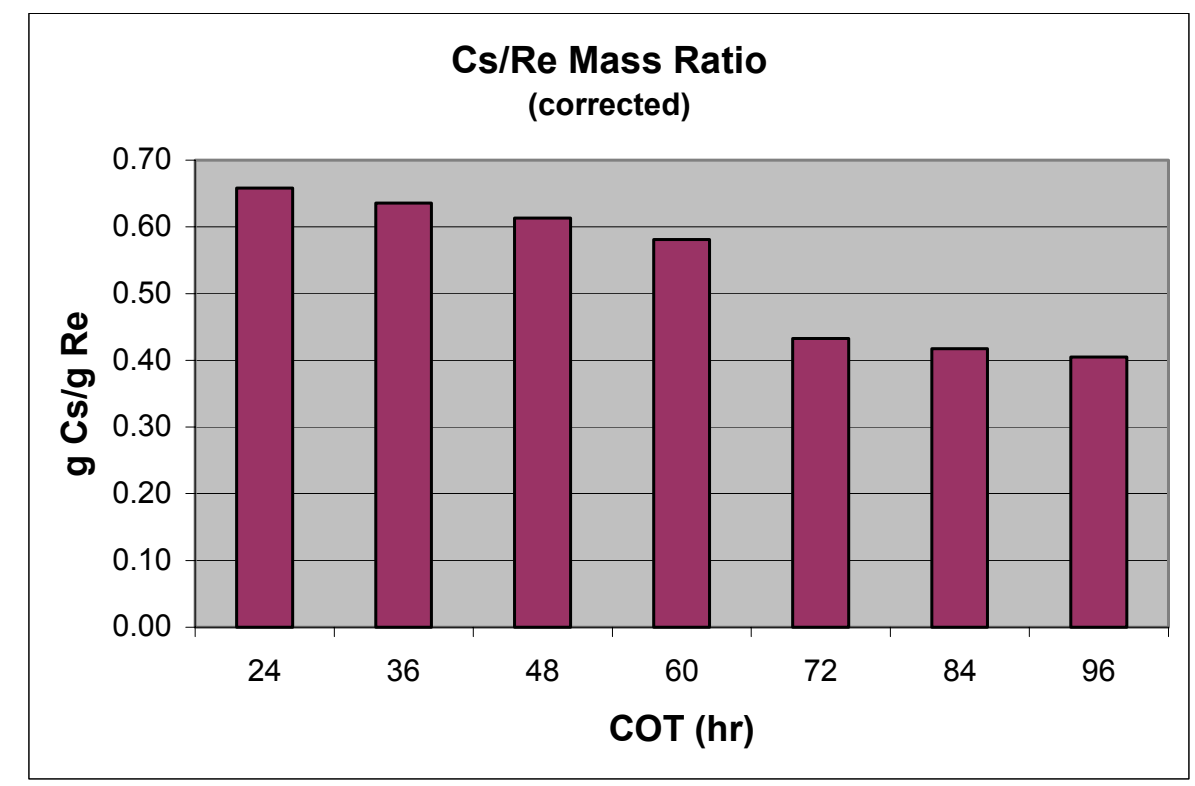

Figure 7. Cesium to rhenium mass ratio in the scrub solution.

\subsection{Fate of Cadmium, Chromium, and Lead}

Cadmium was expressly omitted from the simulant makeup because it is present in the actual WM-180 solution in millimolar concentrations, which doesn't make it chemically significant for the process, but it would pose a significant carcinogenic safety hazard. Fortuitously, cadmium was present in the blended feed in small, but measurable quantities below levels considered toxic under the RCRA. Ninety-six percent of the cadmium was accounted for in the mass balance, all of which was found in the product. No detectable quantities were measured in the bed or in the scrub solution.

Chromium was added to the simulant as trivalent chromium, which is less hazardous than the hexavalent state. While the sample data account for $108 \%$ of the chromium fed to the reformer, $29 \%$ of the recovered chromium remained on the bed medium and $71 \%$ was recovered in the product. Some chromium accumulation was found in the scrub, but this was only $0.02 \%$ of the chromium fed to the process.

Although twice as much lead accumulated in the filter product as in the cyclone product, no detectable lead concentrations were found in the scrub solution, indicating that all volatilized lead species were either trapped on the product particulates or lead vapors condensed on the piping and equipment between the filter and scrubber vessels. The mass balance closure for lead was fair, where only $66 \%$ of the 23.2 grams of lead in the feed were accounted for. Of the lead mass that was found, $27 \%$ remained in the bed and $73 \%$ in the product.

\subsection{Spent Scrub Composition}

The scrub solution used for the demonstration test was a dilute sodium hydroxide solution with an initial $\mathrm{pH}$ of approximately 9 . The $\mathrm{pH}$ remained between 8 and 9 for the duration of the test. No adjustments were made other than operating temperature to control scrub level. During the execution of the demonstration run, the scrub recirculation pump failed. This event happened between cumulative operating time (COT) 60 and COT 72 sampling events. The temperature of the scrubber outlet increased above $100^{\circ} \mathrm{C}$, but the solution remained relatively cool. While the pump was being replaced, the scrub 
solution temperature was decreased to affect some scrubbing by condensing the water vapors.

Temperatures were restored to more normal values after installation of a diaphragm pump to replace the failed centrifugal pump. The replacement pump delivered a pulsating flow of scrub to the venturi, which likely decreased the scrubber efficiency and resulted in a higher scrubber discharge temperature than what had been seen in previous operation. The influence of the modified temperatures on the concentration of species is evident when the compositional change of the scrub solution is examined in Appendix A.

The majority of scrub constituents increased throughout the demonstration run. A few species, however, reached a maximum value and declined sharply toward the end of the run. Fluoride in the scrub reached a maximum after 72 hours of operation and declined by approximately two-thirds within the next 24 hours of operation. Similarly, the undissolved solids (UDS) reached a maximum after 48 hours of operation and lost three-fourths of its value during the remaining 48 hours of operation. The reason for the decline in fluoride concentration is unclear, but the loss in UDS is attributed to capture of particulates in an oily emulsion that accumulated on the top of the scrub solution.

The oily emulsion was a result of the destructive decomposition and reformation of the solid and liquid reductant additives. A sample of the oil phase was submitted for volatile and semi-volatile organic compound (VOC and SVOC) analyses. The laboratory positively identified less than one percent of the mass of the organic phases. The compounds identified are shown in Table 4.

Table 4. Organic compounds identified in the scrubber emulsion.

\begin{tabular}{lrlr}
\hline & \multicolumn{1}{c}{ VOCs } & SVOCs & $\mathrm{mg} / \mathrm{kg}$ \\
\hline Acetone & 2.4 & Phenol & 67 \\
2-Butanone & 0.07 & Naphthalene & 220 \\
Benzene & 4.7 & 2-Methylnaphthalene \\
Toluene & 29 & Acenaphthalene & 890 \\
Ethylbenzene & 9 & Acenaphthene & 390 \\
m-, p-Xylene & 56 & Dibenzofuran & 160 \\
o-Xylene & 24 & Florene & 78 \\
Styrene & 17 & Phenanthrene & 270 \\
$1,1,2,2$, Tetrachloroethane & 0.1 & Fluoranthene & 500 \\
Various alkyl substituted benzenes & 188 & Pyrene & 72 \\
& & Various alkyl substituted 9H-florenes & 27 \\
& & Various substituted naphthalenes & 3,130 \\
\hline Identified VOCs & 330 & Identified SVOCs & 7,694 \\
\hline \hline
\end{tabular}

Total identified organics $=8,024 \mathrm{mg} / \mathrm{kg}$ or $0.8 \mathrm{wt}-\%$ of the emulsion.

\subsection{Product Characteristics}

Product elutriated from the bed was an ash-like powder that was collected in the cyclone separator and in the filter vessel. The product was a freely flowing powder that exhibited some cohesiveness (forms loose clumps that readily break apart as the powder flows). The filter product was aeratable, in that the fines could be mechanically fluidized by shaking and it took a while for the product to settle. Bulk densities were measured for the products as loose, settled (by tapping), and tamped bulk densities. The cyclone product has twice the loose and settled bulk densities of the filter product and tamping increases 
the density by approximately $70 \%$. Densification by tamping increased the filter product density by $160 \%$. Average values are given in Table 5.

Table 5. Average product densities and standard deviations.

\begin{tabular}{lllll}
\hline Product & Loose Density & Settled Density & Tamped Density & Particle Density \\
\hline Cyclone & $0.31 \pm 0.16 \mathrm{~g} / \mathrm{cc}$ & $0.35 \pm 0.18 \mathrm{~g} / \mathrm{cc}$ & $0.54 \pm 0.25 \mathrm{~g} / \mathrm{cc}$ & $1.09_{ \pm 0.06 \mathrm{~g} / \mathrm{cc}}$ \\
Filter & $0.15 \pm 0.01 \mathrm{~g} / \mathrm{cc}$ & $0.17 \pm 0.02 \mathrm{~g} / \mathrm{cc}$ & $0.39 \pm 0.03 \mathrm{~g} / \mathrm{cc}$ & $0.99_{ \pm 0.07 \mathrm{~g} / \mathrm{cc}}$ \\
\hline
\end{tabular}

Cyclone product has the appearance of chopped sponge and hollow spheres that have collapsed. The mean particle size was not determined because of the cohesiveness of the product, but from scanning electron microscope (SEM) photographs, it is evident that the particle sizes range generally from about 15 to $150 \mu \mathrm{m}$. SEM micrographs of cyclone product are shown in Figures 8 and 9.

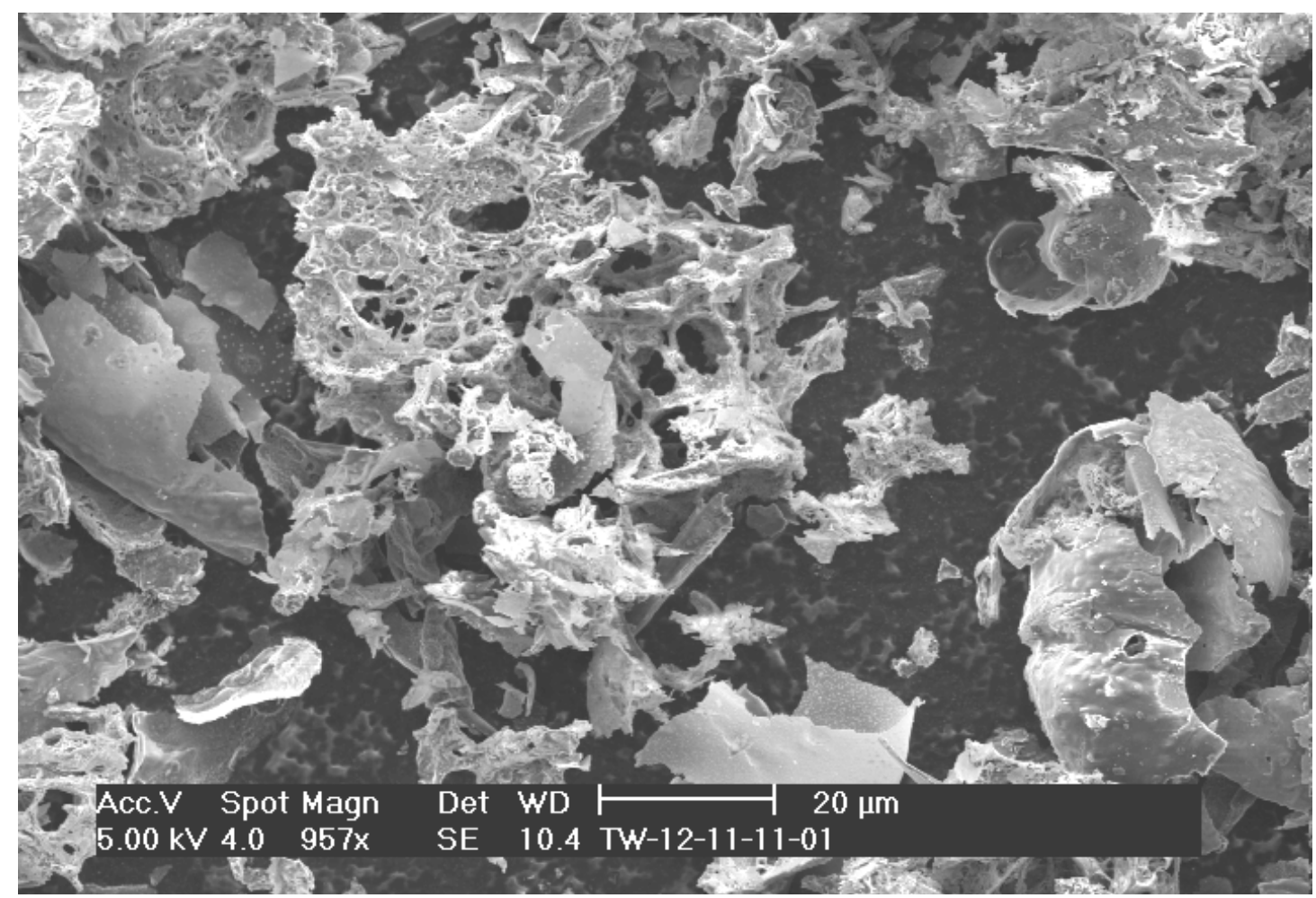

Figure 8. SEM micrograph of cyclone product. 


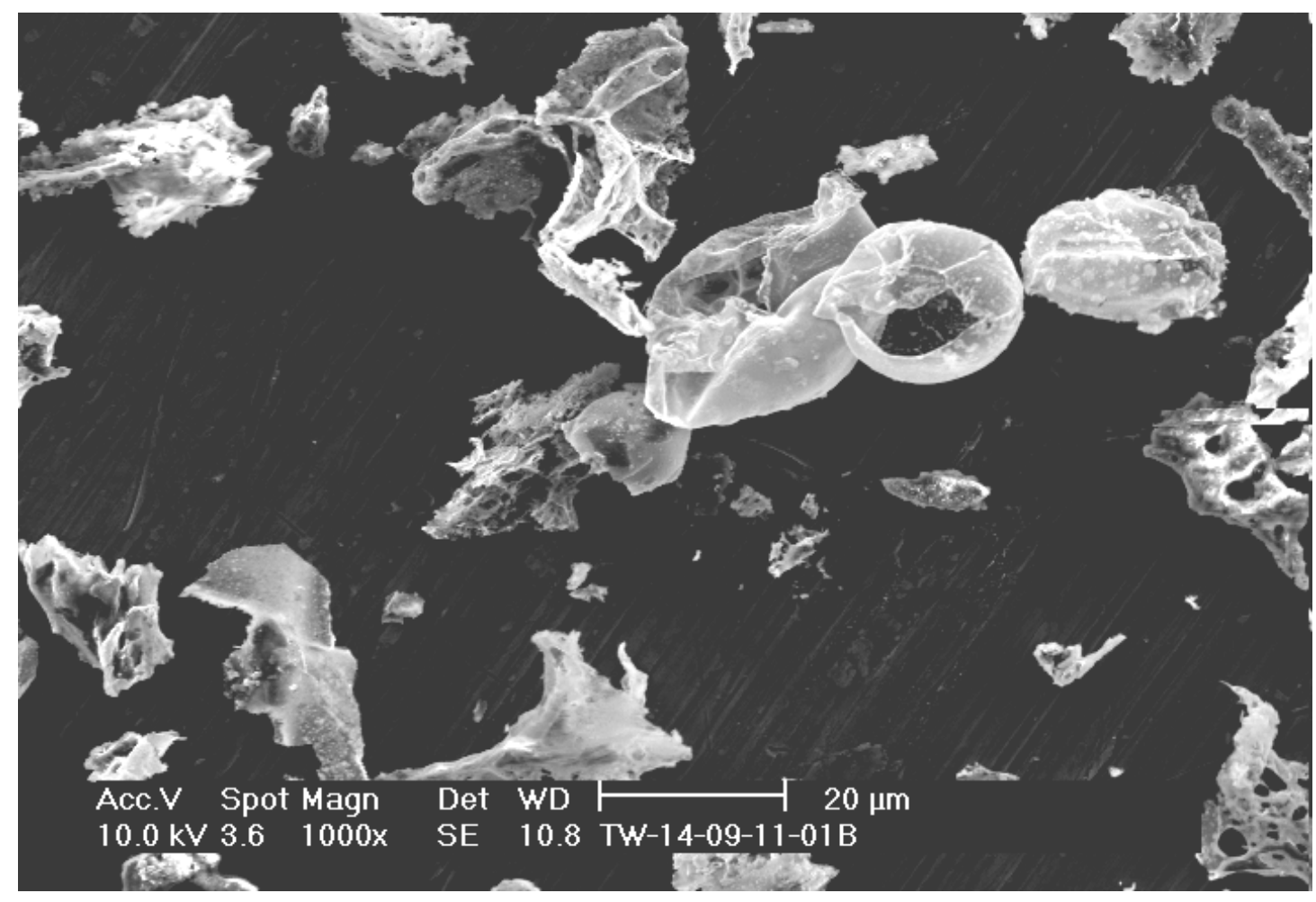

Figure 9. SEM micrograph of cyclone product.

The filter product has much the same appearance as the cyclone product (i.e., a mixture of spongy fragments and spheres) with somewhat planer fragments as well. The particle size seems to be predominantly less than $15 \mu \mathrm{m}$. An example of the filter product is shown in Figure 10.

The carbon content of the product streams is shown in Table 6. Elemental carbon (char) produced in the reformer from the pyrolysis of the solid and liquid reductant additives. Inorganic carbon is from the carbonate salts and organic carbon exists as semi-volatile and sorbed pyrolysis products. As would be expected, the filter fines have the highest percentage of total carbon and the bed has the lowest percentage. Values for inorganic and organic carbon content in the cyclone and filter products are not statistically different. The char and organic carbon in the cyclone and filter products represent unused reductant. An optimization of the process that either reduced the feed rate of total reductants, or improves the utilization of the reductant mass to destroy $\mathrm{NO}_{\mathrm{x}}$, could result in lower amounts of char and organic carbon in the solid products. An increase in the reformer temperature and/or residence time in the reactor should reduce the organic carbon content in the solid residues. 


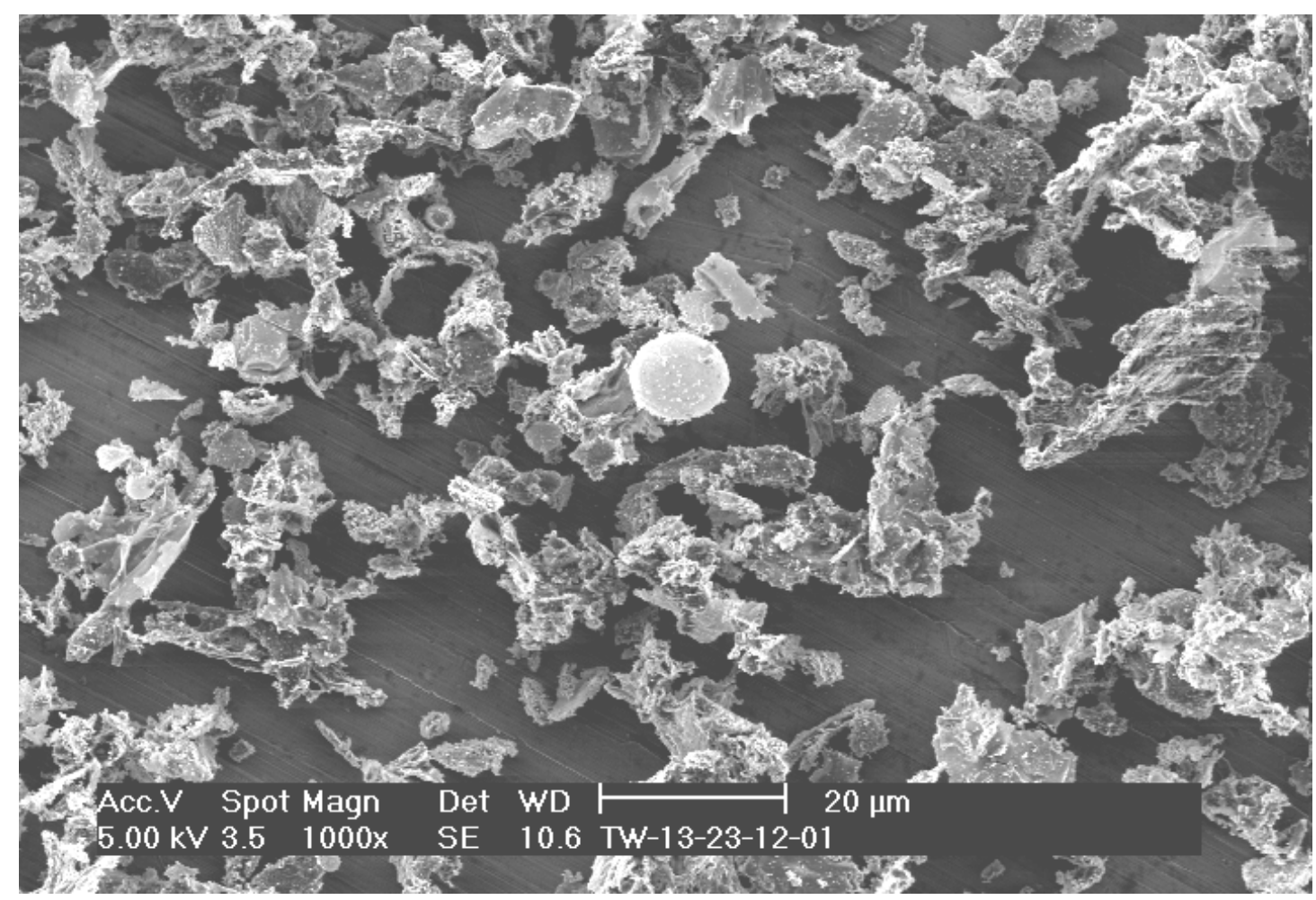

Figure 10. SEM micrograph of filter product.

Table 6. Product carbon and ash content composition.

\begin{tabular}{lccc}
\hline \multicolumn{1}{c}{ Analysis } & Bed Product & Cyclone Product & Filter Product \\
\hline Elemental Carbon & $0.022 \pm 0.006 \%$ & $1.6 \pm 0.8 \%$ & $3.8 \pm 1.6 \%$ \\
Inorganic Carbon & $0.07 \pm 0.03 \%$ & $5.4 \pm 1.0 \%$ & $5.3 \pm 1.7 \%$ \\
Organic Carbon & $0.43 \pm 0.06 \%$ & $2.5 \pm 1.2 \%$ & $2.8 \pm 1.2 \%$ \\
Total Carbon & $0.52 \pm 0.08 \%$ & $9.5 \pm 1.1 \%$ & $11.9 \pm 2.6 \%$ \\
Total Ash & $93.3 \pm 5.9 \%$ & $83.8 \pm 8.2 \%$ & $67.8 \pm 4.0 \%$ \\
Number of Samples & 2 & 8 & 7 \\
Chief Crystalline Phases & Bed Medium & $\mathrm{Bed} \mathrm{Medium} \%$ & $\mathrm{Bed} \mathrm{Medium} \%$ \\
& & $\mathrm{Na}_{1.8}\left(\mathrm{Mg}_{0.9} \mathrm{Si}_{1.1} \mathrm{O}_{4}\right)$ & $\mathrm{Na}_{1.8}\left(\mathrm{Mg}_{0.9} \mathrm{Si}_{1.1} \mathrm{O}_{4}\right)$ \\
& & $\mathrm{Na}_{1.9} \mathrm{Al}_{1.95} \mathrm{Si}_{0.05} \mathrm{O}_{4}$ & $\mathrm{Na}_{1.9} \mathrm{Al}_{1.95} \mathrm{Si}_{0.05} \mathrm{O}_{4}$ \\
\hline
\end{tabular}

Data show that several of the metals in the feed were somewhat volatile under the process conditions as evidenced by a disproportionate deposition of these metals in the filter product as compared to the cyclone product. Non-volatile species appear slightly depleted in the filter product, due to a higher fraction of elemental carbon in the product. The most volatile species (those with the most enrichment in the filter product) were the ammonium, cadmium, cesium, lead, zinc, and zirconium compounds. While cadmium, zinc, and zirconium were not intentionally added to the simulant, it is apparent that they were present as measurable contaminants in the chemicals used for the makeup. Graphical presentations of the data are shown in Appendix B.

The bed medium darkened with use, turning to a nearly black, angular powder. Accumulations of non-volatile metals ranged from one-quarter to one-third of the mass fed to the reactor. The deposits on 
the particles (Figure 11) are expected to be metal carbonate salts with inclusions of elemental carbon. Any carbonates, however, are present in amorphous masses.

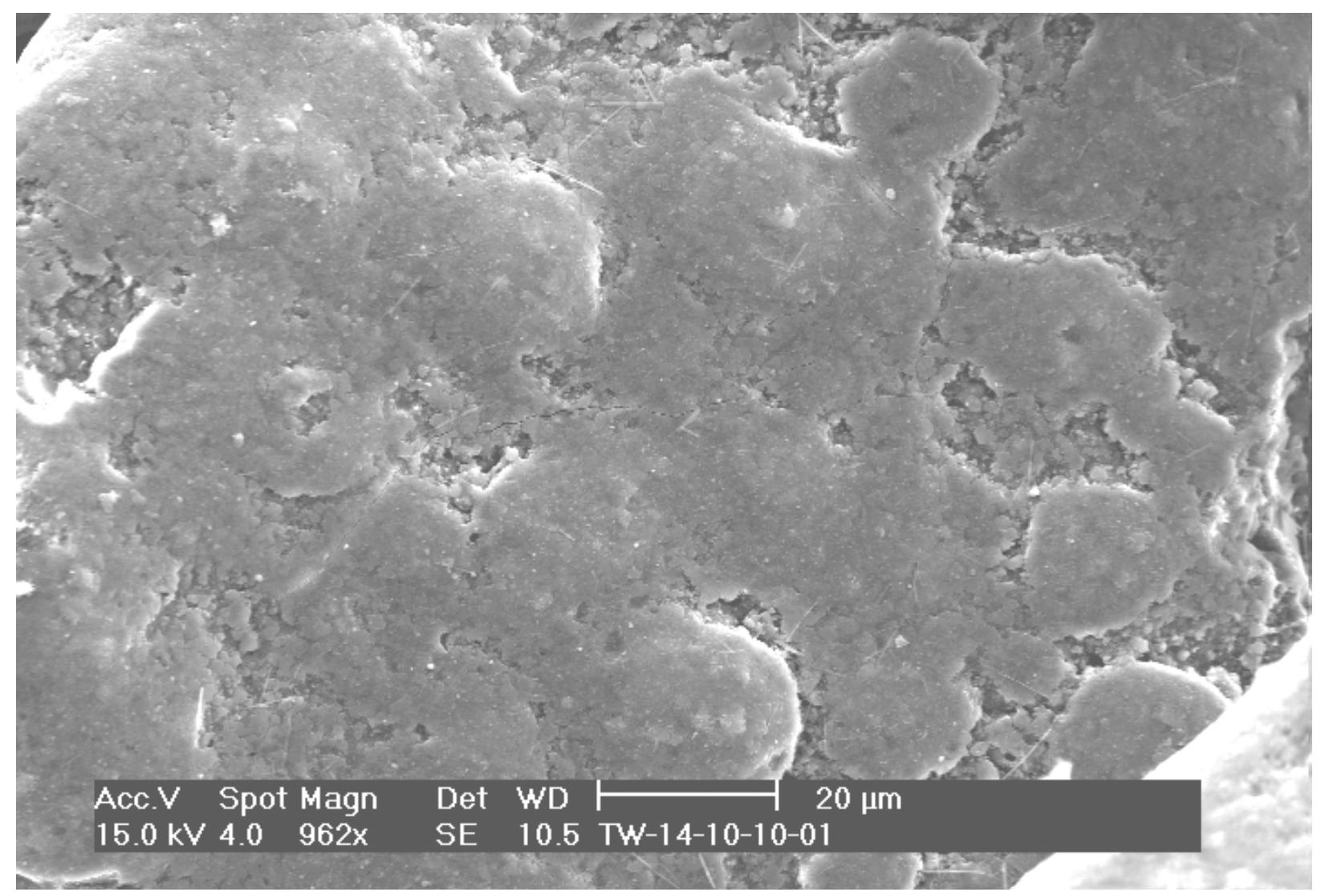

Figure 11. SEM micrograph of a used bed particle surface.

The feed to the process was a blend of SBW simulant and liquid additive that was kept at a constant net SBW feed rate of $0.90 \mathrm{~L} / \mathrm{hr}$. A total of 89.4 liters $(112.6 \mathrm{~kg})$ of SBW simulant was processed during the demonstration run. In the table below, only the product catch from the 100-hr demonstration is considered. It should be noted that about one-third of the product accumulated on the bed medium. It is unknown whether the product inventory on the bed medium would continue to rise, resulting in the eventual displacement of the starter bed as product is taken off the reformer bottom or that the inventory would reach a stable steady state value with no product takeoff. The SBW mass and volume reductions are given below, with the assumptions that the mass of the initial starter bed would be inconsequential and that the bulk density of the bed does not change with time. Only the settled and tamped bulk densities are considered in Table 7 because process vibrations and the weight of the product column in the waste canister would partially compact the product, thus making the loose density irrelevant to waste storage and shipping concerns. Optimization of the reformer temperature, residence time, fluidization velocity, reductant additions, etc. should facilitate greater mass and volume reductions. 
Table 7. Waste volume and mass reduction data.

\begin{tabular}{|c|c|c|c|}
\hline \multicolumn{4}{|l|}{ FEED DATA } \\
\hline Equivalent SBW Vol. Rate & $0.9 \mathrm{~L} / \mathrm{hr}$ & Equivalent SBW Mass Rate & $1.13 \mathrm{~kg} / \mathrm{hr}$ \\
\hline Total SBW Vol. Processed & $89.4 \mathrm{~L}$ & Total SBW Mass Processed & $112.6 \mathrm{~kg}$ \\
\hline \multicolumn{4}{|l|}{ PRODUCT DATA } \\
\hline Recovered Bed Mass & $59.7 \mathrm{~kg}$ & \multicolumn{2}{|l|}{ Product Distribution } \\
\hline Virgin Bed Mass & $54.1 \mathrm{~kg}$ & Bed & $32 \mathrm{wt} \%$ \\
\hline Bed Product Inventory & $5.6 \mathrm{~kg}$ & Cyclone & $35 \mathrm{wt} \%$ \\
\hline Cyclone Product Mass & $6.3 \mathrm{~kg}$ & Filter & $33 \mathrm{wt} \%$ \\
\hline Filter Product Mass & $5.9 \mathrm{~kg}$ & & \\
\hline Total Product & $17.8 \mathrm{~kg}$ & & \\
\hline \multicolumn{2}{|c|}{ PRODUCT MASS/SBW MASS } & \multicolumn{2}{|c|}{ PRODUCT VOLUME/SBW VOLUME } \\
\hline & & Settled Product & Tamped Product \\
\hline Bed & $0.050 \mathrm{~kg} / \mathrm{kg}$ & $0.03 \mathrm{~L} / \mathrm{L}$ & $0.03 \mathrm{~L} / \mathrm{L}$ \\
\hline Cyclone & $0.056 \mathrm{~kg} / \mathrm{kg}$ & $0.20 \mathrm{~L} / \mathrm{L}$ & $0.13 \mathrm{~L} / \mathrm{L}$ \\
\hline Filter & $0.052 \mathrm{~kg} / \mathrm{kg}$ & $0.39 \mathrm{~L} / \mathrm{L}$ & $0.17 \mathrm{~L} / \mathrm{L}$ \\
\hline Total Product & $0.158 \mathrm{~kg} / \mathrm{kg}$ & $0.62 \mathrm{~L} / \mathrm{L}$ & $0.33 \mathrm{~L} / \mathrm{L}$ \\
\hline \multicolumn{2}{|l|}{ Mass Reduction } & \multicolumn{2}{|l|}{ Volume Reduction } \\
\hline $84.2 \%$ & & $38 \%$ & $67 \%$ \\
\hline
\end{tabular}

\section{DISCUSSION AND ANALYSIS}

CEM measurements were performed to measure for $\mathrm{O}_{2}, \mathrm{CO}_{2}, \mathrm{CO}, \mathrm{NO}, \mathrm{NO}_{\mathrm{x}}, \mathrm{H}_{2}$, and $\mathrm{CH}_{4}$ in the steam reformer off-gas between the heated filter and the venturi scrubber. At this sample location, the off-gas was diluted with some purge $\mathrm{N}_{2}$ and added dilution $\mathrm{N}_{2}$. The dilution $\mathrm{N}_{2}$ lowered the $\mathrm{H}_{2}$ concentration in the sample gas, assuring that the $\mathrm{H}_{2}$ concentration did not pose an explosion or flammability hazard when moisture was removed from the sample gas in the sample conditioner.

As expected, the steam reformer off-gas had essentially no $\mathrm{O}_{2}$. Without the dilution $\mathrm{N}_{2}$, CO levels averaged $0.3 \%$ while the measured $\mathrm{CH}_{4}$ levels averaged $1.6 \%$. Other hydrocarbon species including condensable hydrocarbons were detected in the scrubber solutions but not quanitified.

The $\mathrm{H}_{2}$ content in the off-gas was low, averaging about $0.8 \%$. At all times, the $\mathrm{H}_{2}$ level was well within safe operating limits. The highest measured $\mathrm{H}_{2}$ concentration normalized to a dry, $\mathrm{N}_{2}$-free basis was $1.4 \%$, about one-third of the LFL of $4 \%$ in air. Actual $\mathrm{H}_{2}$ concentrations on a wet basis with $\mathrm{N}_{2}$ dilution were only about half as high as the dry, $\mathrm{N}_{2}$-free values.

Off-gas $\mathrm{NO}$ and $\mathrm{NO}_{\mathrm{x}}$ concentrations (dry, $\mathrm{N}_{2}$-free basis) averaged about $830 \mathrm{ppm}$ and $860 \mathrm{ppm}$, respectively. The difference between the average $\mathrm{NO}$ and $\mathrm{NO}_{\mathrm{x}}$ concentrations (about $30 \mathrm{ppm}$ ) was the average $\mathrm{NO}_{2}$ concentration. Other $\mathrm{N}_{\mathrm{x}} \mathrm{O}_{\mathrm{y}}$ species including $\mathrm{HNO}_{3}, \mathrm{~N}_{2} \mathrm{O}$, and $\mathrm{NH}_{3}$ were not speciated in the analysis, and the $\mathrm{NO}_{\mathrm{x}}$ concentration data have been adjusted to eliminate potential positive biases from 
detection of these species or other non-nitrogen species as $\mathrm{NO}_{\mathrm{x}}$. $\mathrm{NO}$ and $\mathrm{NO}_{\mathrm{x}}$ reduction for the entire 100 -hr run averaged $86.6 \%$ and $86.3 \%$, respectively.

\section{CONCLUSIONS}

The reforming process performed reliably well. No bed agglomerations were observed and the reactor temperatures remained uniform. The process is inherently safe due to the absence of oxidizing or strongly exothermic reactions in the bed and the low hydrogen concentration in the off-gas. Should the feed or reductant addition be interrupted, the bed and heater temperatures will increase only slightly before the control system will decrease power input to the heaters, thus maintaining the temperatures near the set point. This architecture provides for converging solutions at all times and avoids system divergence, which could lead to a potentially unsafe condition.

Most of the product elutriated from the bed, as expected, with some accumulation on the bed medium. This accumulation on the bed medium, if confirmed with long duration testing, could be reduced by increasing the distributor and atomizing gas exit velocities to promote attrition and subsequent elutriation of the product. The bed medium, however, is less prone to attrition and elutriation because of its relative particle hardness and density.

The pyrolysis of the solid reductant and liquid additive produced a reducing environment sufficient to achieve over $86 \% \mathrm{NO}_{\mathrm{x}}$ destruction and successfully achieved a total $\mathrm{NO}_{\mathrm{x}}$ concentration below 1,000 ppmv (dry, $\mathrm{N}_{2}$-free basis). Of the measured $\mathrm{NO}_{\mathrm{x}}$ species emitted, $\mathrm{NO}$ was the most prevalent. These $\mathrm{NO}_{\mathrm{x}}$ levels were low enough that they should not interfere with emissions monitoring. Hydrogen concentrations in the off-gas were low enough that they do not pose a threat of forming an explosive mixture.

While the process achieved substantial $\mathrm{NO}_{\mathrm{x}}$ reduction, TWR believes even greater $\mathrm{NO}_{\mathrm{x}}$ reduction can be achieved by performing kinetic evaluations and process simulations. TWR personnel had expected higher hydrogen production, which would have enhanced $\mathrm{NO}_{\mathrm{x}}$ destruction. Hydrogen production could be enhanced by increasing the operating temperature. If local environmental emission limits require additional $\mathrm{NO}_{\mathrm{x}}$ reduction, TWR suggests consideration be given to incorporating an appropriate selective catalytic reduction (SCR) technology.

The product was a dry powder that flows freely and was somewhat aeratable and cohesive. The low density of the product will necessitate some form of product densification to achieve adequate waste loading. Vibratory compaction may not be adequate to achieve significant densification. Mechanical compaction, however, can achieve a 50 to $100 \%$ increase in the density. The product is expected to absorb moisture from the atmosphere, which could cause crystal growth and consolidation of the product at exposed surfaces. The cyclone and filter products contained 1.6 to $3.8 \mathrm{wt} \%$ elemental carbon, respectively, and more than $2.5 \mathrm{wt} \%$ organic carbon. An increase in residence time (e.g., cyclone catch recycle) in the reactor coupled with a decrease in solid reductant feed should reduce unconverted carbon and improve volume reduction.

Volatile metals were mostly retained in the products, more especially in the filter product, with very little escaping in the off-gases, except for mercury. Mercury was reduced to the elemental state and was not readily absorbed by the product or the scrub solution. In these tests, mercury sorption on the GAC column was inhibited by organic byproducts of solid reductant pyrolysis, which would not have been the case if a thermal oxidation unit had been installed in the off-gas treatment train. Approximately 
$99.9 \% \%^{3}$ of the cesium and rhenium were retained in the bed and the product with less than $0.1 \%$ being collected in the scrub solution.

Process throughput was slow because the SBW simulant was blended with a liquid additive and fed to the reactor at a rate equivalent to 0.9 liters of SBW simulant per hour. The temperature data indicate that a higher process throughput can be achieved without challenging the reactor wall temperature limit. Some additional increase in throughput could be realized by installing an immersion heater in the bed. The extent to which the feed rate can be increased can be estimated, but how nearly the wall temperature limit can be approached needs to be determined experimentally.

The solid reductant addition rate to the process, during the demonstration run, was double the rate TWR had originally planned to use. This was a conservative response to interpretations of process operations during initial testing. The bed material and the cyclone and filter catches all appeared gray to black in color; indicative of elemental carbon being present. Development tests conducted independently by MTCI resulted in used bed material that showed no significant darkening, which suggests little or no residual carbon. The carbon residues in the bed observed after the demonstration test may be a consequence of the high solid reductant addition rate that TWR recommended in response to unexpected $\mathrm{NO}_{\mathrm{x}}$ emissions. For a brief period at the end of the demonstration run, the solid reductant addition rate was cut in half to see if a noticeable difference in bed color would be observed. CEM data showed a decrease in the methane concentration from 2.5 to 0.9 vol.\%, about a $10 \%$ increase in $\mathrm{NO}_{\mathrm{x}}$ concentrations, and what appeared to be reduced product accumulation rates in the cyclone and filter catches. It is anticipated that process optimization will reduce the carbon residues and increase mass and volume reductions. It is, however, preferred that the bed material be gray or slightly dark for enhanced radiant heat transfer.

The pneumatic solids injection system or shotgun was acceptable for the solid reductant injection, but did provide unsteady or uneven injection rates into the bed on a short-term basis. The metering screw did not provide a steady discharge of reductant into the injector. The irregular solid reductant addition rate may have coupled with the dynamics of the fluidized bed to cause the off-gas composition (especially methane) to vary in a somewhat cyclical manner. TWR suggests that a water/steam cooled injection screw mounted closer to the distributor would facilitate uniformity in the reductant addition and enhance residence time for greater $\mathrm{NO}_{\mathrm{x}}$ reduction.

The demonstration run was of sufficient duration to show that the process was stable and could be reliably operated using the TWR reforming technology, but was not long enough to determine whether the deposits on the bed medium would continue to accumulate or reach a steady state inventory. By the specified objectives in Section 1.2, the demonstration of the TWR reforming technology was a success.

\footnotetext{
${ }^{3}$ Approximately $20 \%$ of the cesium was unaccounted for in the mass balance, but volatilized cesium should have been efficiently removed from the off-gas by the scrubber. It is assumed that the missing cesium is a consequence of the difficulty in getting representative solids samples and due to the relatively small quantity of cesium in the feed. Rhenium recovery was about $140 \%$ of what was fed to the process, mostly on the bed medium. The removal efficiency is based on the quantity recovered in the scrub relative to that known to have been fed to the process.
} 


\section{REFERENCES}

Barnes, Charles M., 2001. "Feed Composition for the Sodium-Bearing Waste Treatment Process," INEEL/EXT-2000-01378, Revision 1.

EPA, 2002, Method 6C, "Determination of Sulfur Dioxide Emissions from Stationary Sources (Instrumental Analysis Procedure)," 40 CFR 60, Appendix A.

Holman, J. P., 1978, “Experimental Methods for Engineers,” McGraw-Hill Book Company, New York.

Joyce, Helen, 2003, "Mixed Waste Technology Program Final Report - Sorbents to Capture Volatile Organic Compound Emissions from OASIS Radioactive Sludge $140^{\circ} \mathrm{F}$ Tests," MSE Technology Applications.

Marshall, D. W., 2002, “TWR Steam Reforming Demonstration Test Plan.”

Soelberg, Nick, 2003, "Offgas Mercury Control for the Idaho Tank Farm Project - Calcination with MACT Upgrade SBW Treatment Alternative," INEEL EDF-3292, Revision 0.

Summers, R. L., 1976, " $\mathrm{NO}_{\mathrm{x}}$ Destruction by $\mathrm{CO}$ in $\mathrm{NO}_{\mathrm{x}}$ to $\mathrm{NO}$ Converters of Chemiluminescent $\mathrm{NO}$ Analyzers,” NASA Technical Memorandum NASA TM X-73480.

\section{APPENDIXES}

Appendix A, Scrub Solution Composition

Appendix B, Product Composition

\section{PROPRIETARY ADDENDA}

Proprietary Addendum 1, TWR Steam Reforming Demonstration Report Extracts

Proprietary Addendum 2, Continuous Emissions Monitor Data

Proprietary Addendum 3, ThermoChem Waste Remediation, L.L.C. Document 


\section{APPENDIX A \\ Scrub Solution Composition}


The scrubber solution level varied over time as a function of the scrub solution temperature and the scrubbing efficiency. The solution temperature was manually controlled in an attempt to achieve water neutrality (no net water condensation or evaporation). When the scrub pump failed and was replaced with a diaphragm pump, the scrubbing efficiency decreased because the scrub solution flow was unsteady. This necessitated that operators seek a new steady state scrub temperature. Dissolved solid concentrations changed inversely proportional to the scrub volume. Values of the analytes have been normalized based on the scrub level and reported along with the raw data for comparison.
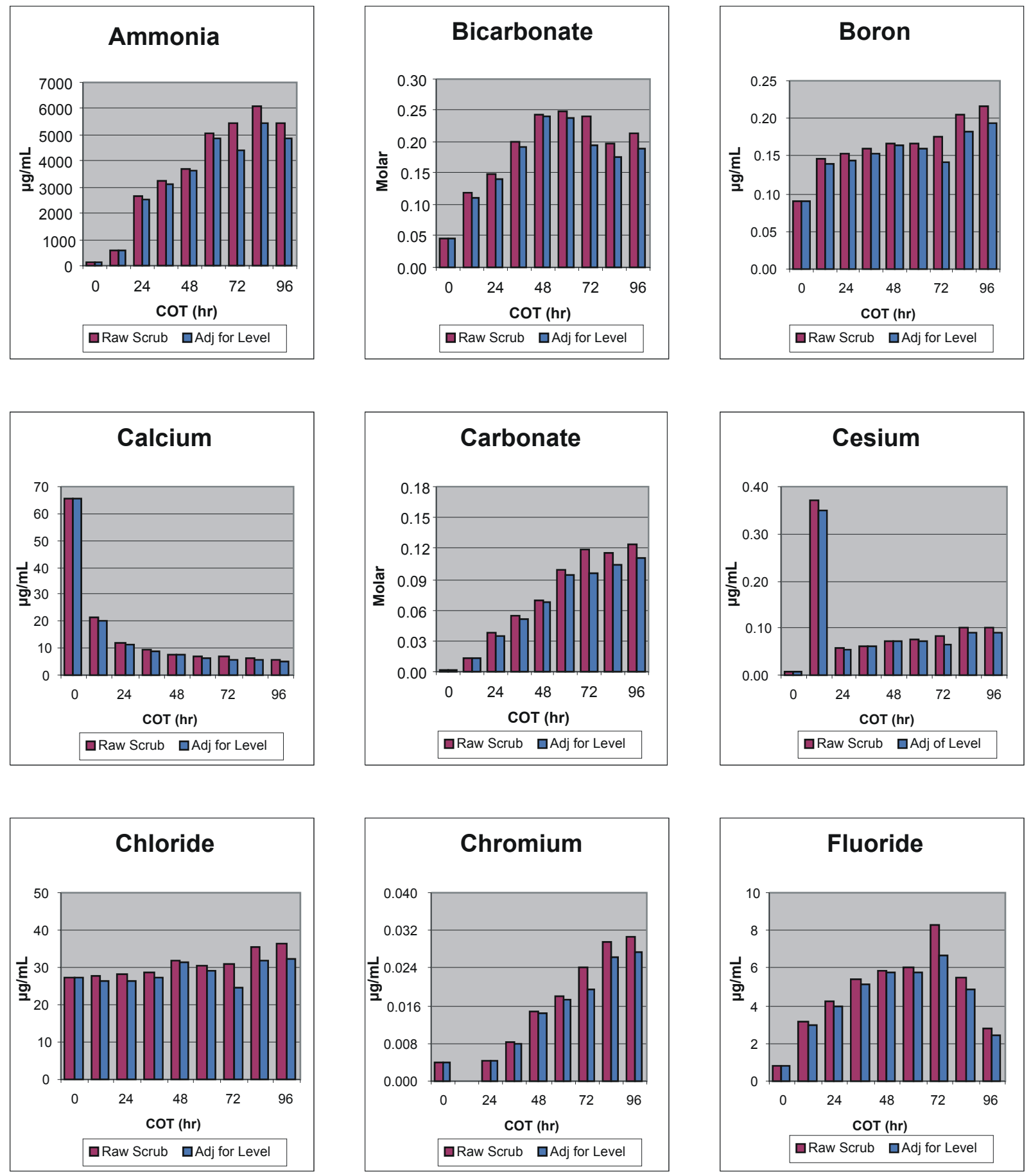

03-GA50602-01 

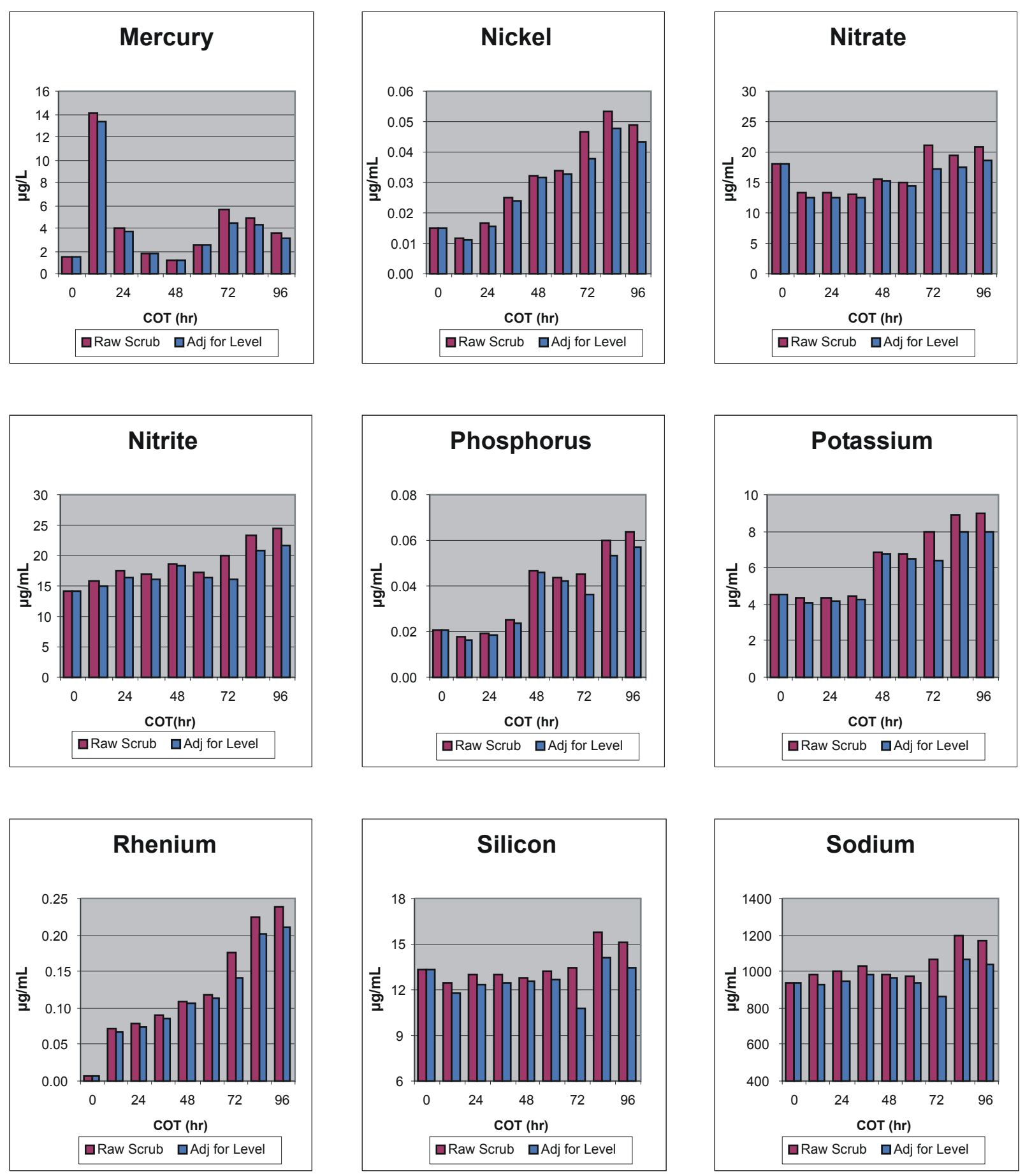

03-GA50602-02 

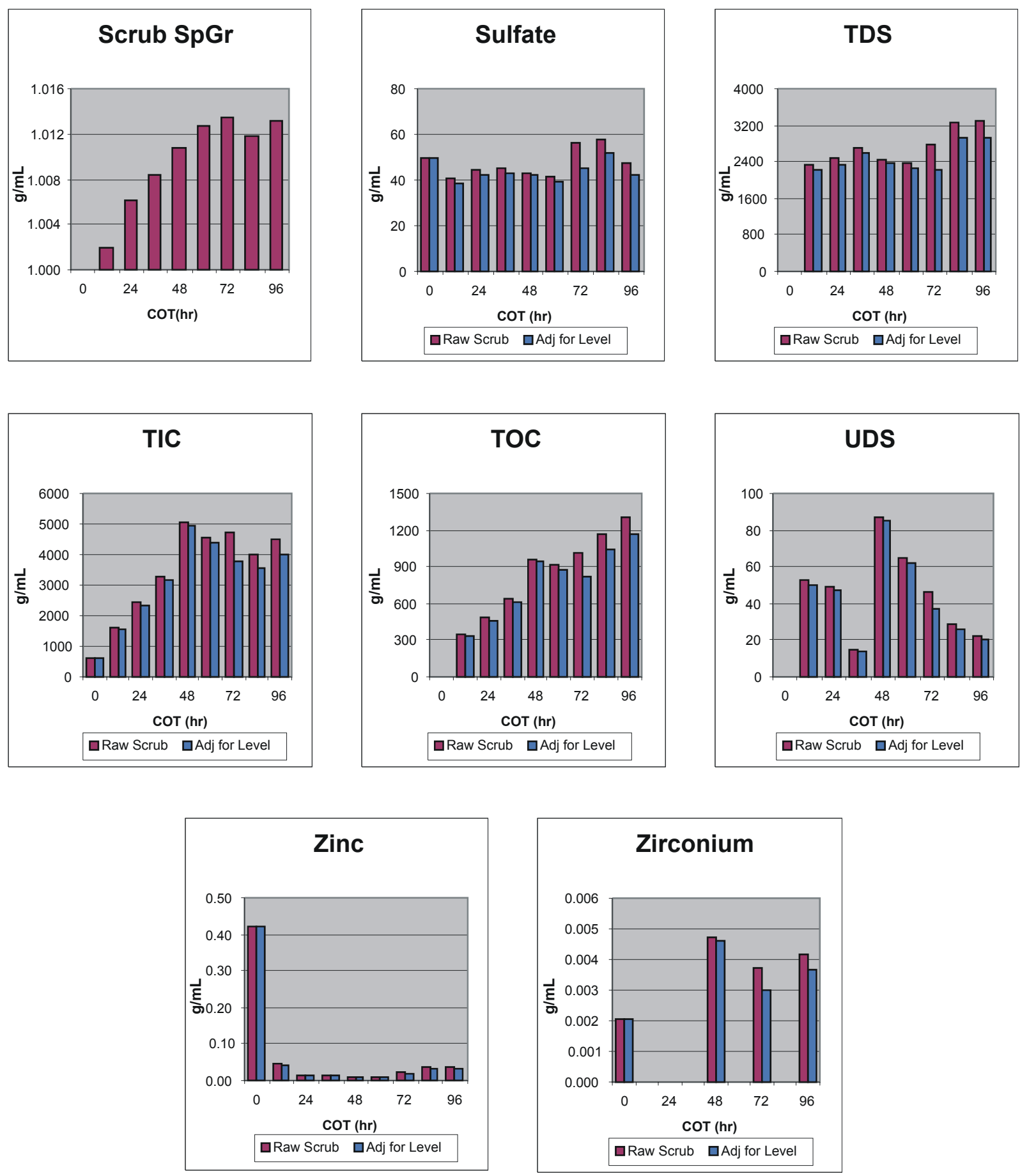

03-GA50602-03 


\section{APPENDIX B}

\section{Product Composition}



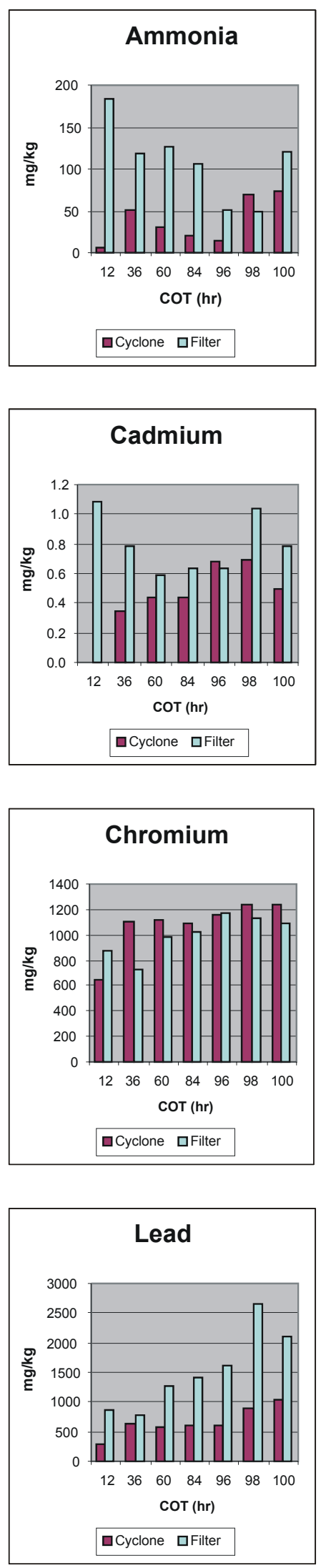
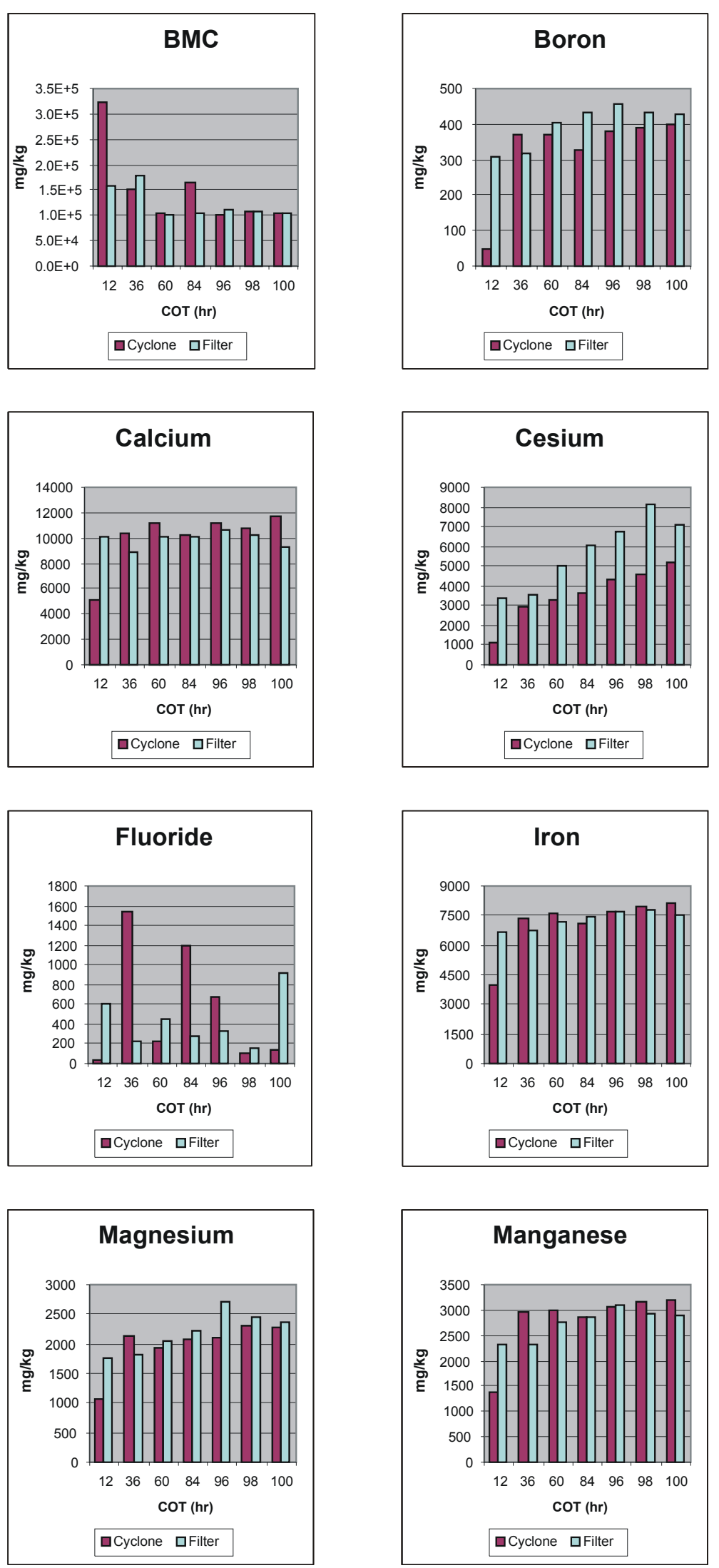

03-GA50602-04

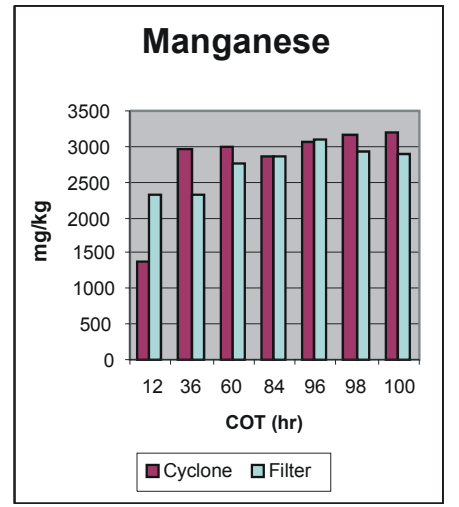



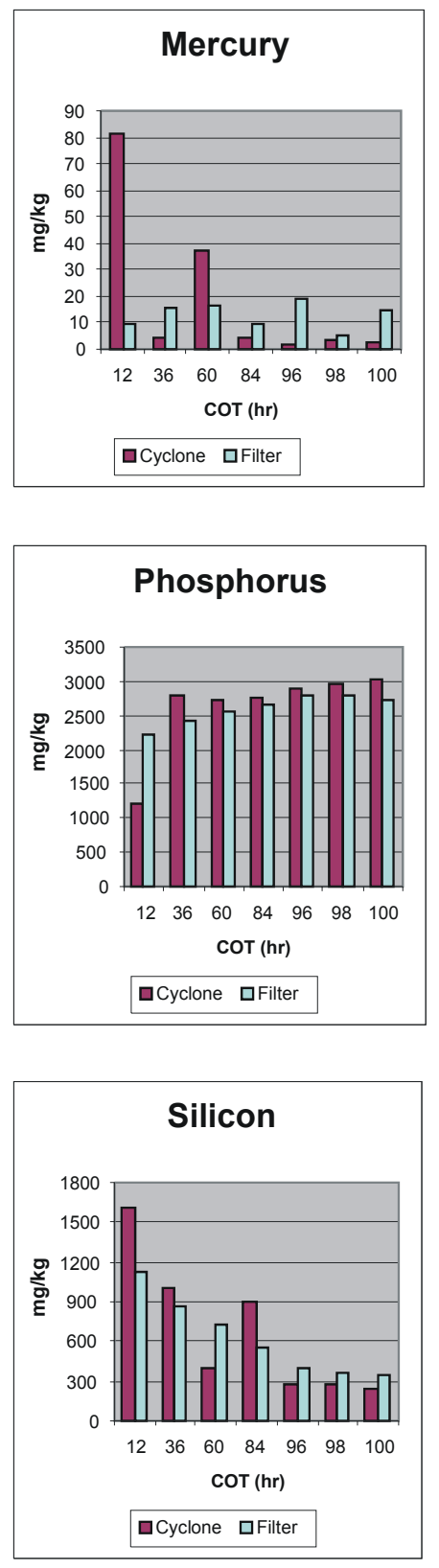
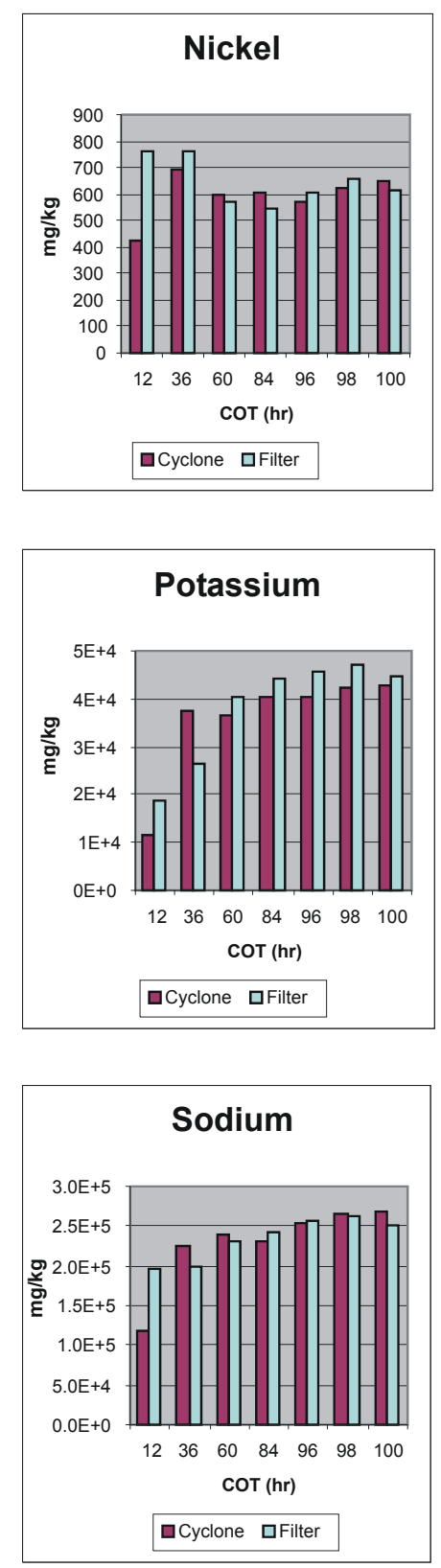
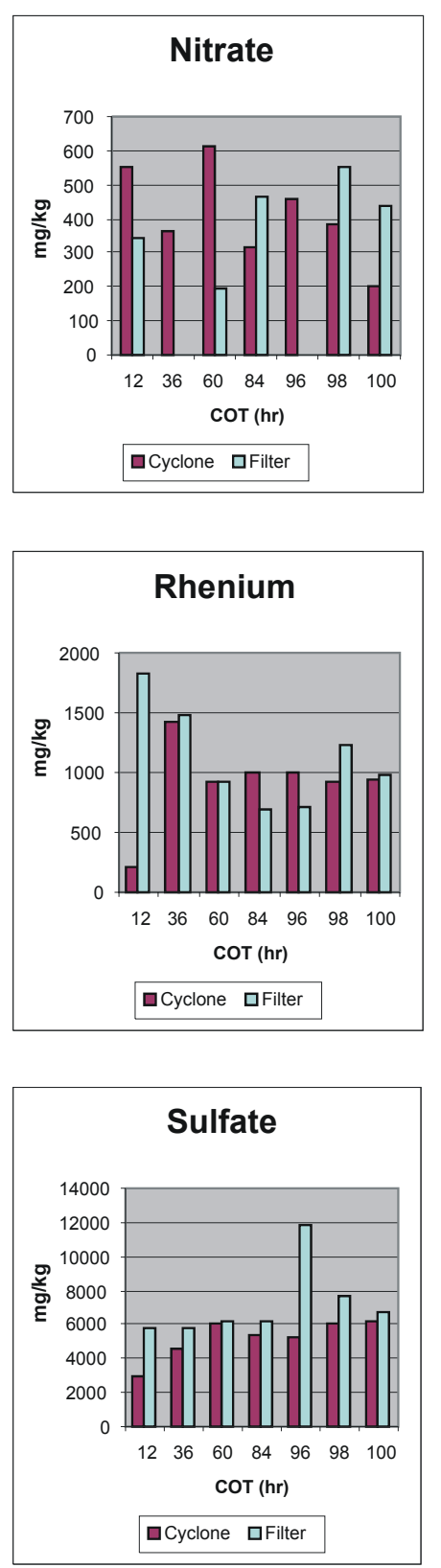
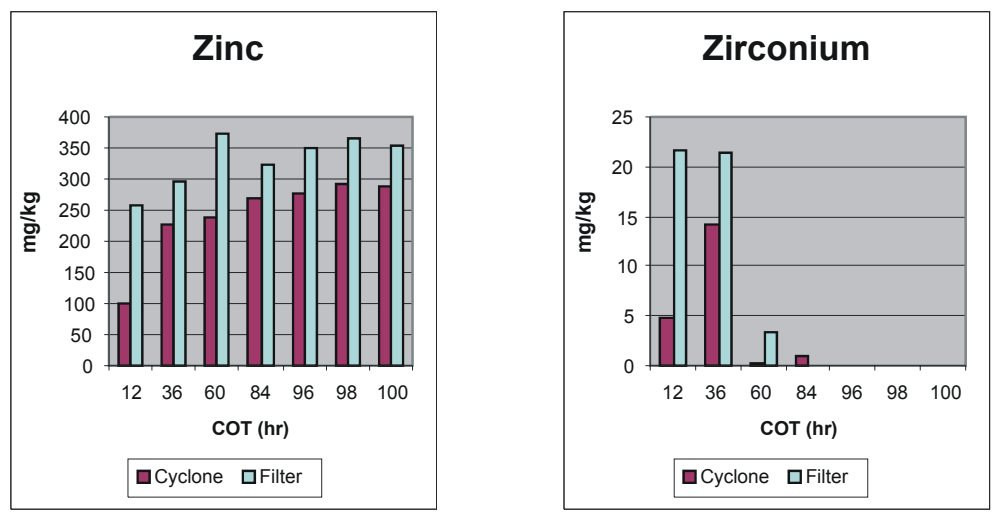